\title{
REVIEW
}

\section{Congruent biospheric and solar-terrestrial cycles}

\author{
Germaine Cornélissen ${ }^{1}$, Patricia Grambsch ${ }^{1}$, Robert Bruce Sothern ${ }^{1}$, George Katinas ${ }^{1}$, Kuniaki Otsuka ${ }^{2}$, \\ Franz Halberg ${ }^{1 *}$ \\ ${ }^{1}$ University of Minnesota, Minneapolis, USA \\ ${ }^{2}$ Tokyo Women’s Medical University, Tokyo, Japan
}

Received $6^{\text {th }}$ March 2010.

Revised 29 $9^{\text {th }}$ June 2010.

Published online $27^{\text {th }}$ July, 2010.

\begin{abstract}
Summary
Selective congruence, namely a pairing of various biospheric cycles of certain frequencies with different environmental ones and further selectivity of phase behavior at the given frequency characterize an ultradian to infradian, prominently circadian transdisciplinary spectrum. Diseases documented among others to be influenced by the cosmos range from individuals' strokes to populations' crime and terrorism, conditions studied by chronomics as time structures (chronomes). Methods of investigation include the extended cosinor allowing for the added estimation of the period with a measure of uncertainty, as well as global and gliding spectral windows complemented by chronobiologic serial sections. These methods estimate, each of them with uncertainties, changes as a function of time in weather on earth and in space on the one hand and in human personal and broader affairs on the other. They further map features of these time structures that may change as a function of time in a logically consistent way. Associations of several biological time series with physical environmental variables are presented herein, as are methods used for their investigation and a statistical assessment of their congruence.
\end{abstract}

Key words: biosphere; chronome; congruence; cosmos; transdisciplinary approach

* Dedicated by the last-named to the first-named author on the occasion of her birthday on November 22, 2009.

\section{INTRODUCTION}

The brain's action potentials are faster than those of the heart. The gut's movements, certainly its refilling and evacuation, are much slower. Reproduction is

$\bowtie \quad$ Germaine Cornélissen, Halberg Chronobiology Center, University of Minnesota MMC 8609, 420 Delaware Street SE, Minneapolis, MN 5545, USA

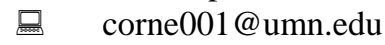

涌 612-624-6976

圆 612-624-9989 slower yet. Living matter functions concomitantly on vastly different frequencies, as a system open to its environment. Hence a host of cycles external to the organism influences it, sharing its frequencies but not necessarily its phases. This is best documented for a circadian system, which when synchronized in period (which happens to coincide with the earth's rotation around its axis) can show differences in phase representing a division of labor in time. Likewise, about 5-month cycles in 15 years of mostly daily data on the volume of urine of a healthy man and on his steroidal metabolites can share their period with both relative sunspot numbers (Wolf or Zürich numbers, International Sunspot Count, or Brussels SIDC Index) and geomagnetism, but can follow different phases, 
steroids traveling with a planetary geomagnetic index and urine volume, perhaps, locking in transiently with sunspots.

There are solar-interplanetary-terrestrial associations with human health versus disease, long claimed and descriptively documented by leaders of genius in the field of in the past, such as Chizhevsky (1921), and at present by Mikulecký (2007) and Ertel (1996). They recognized that health includes economic, political and climatic well-being and that all aspects of the biosphere depend on weather on earth and in space.

Time structures of environmental and biological variables can be resolved as consisting of chaos, trends and/or cycles. Resolution of the latter depends on the sampling density and on the length of time series. When cycles around and in us are being compared in spectra, the non-stationarity of components must be assessed. Some of these cycles were described as quasi-periodic or quasi-persistent because of their variability that can include transient failures to detect them. We separate these cycles into photics, related to electromagnetic radiation in the visible domain, and non-photics, including particle radiation from the sun and the associated helio-, interplanetary, ionospheric- and geo-magnetics, UV flux, gravity and everything else invisible that is meaningfully measurable in the cosmos. We focus on infradian cycles with periods longer than 28 hours. (Circadian aspects - periods between 20 and 28 hours - that also include "non-photic" space weather-related as well as feeding schedules, and ultradians, periods shorter than 20 hours, that also have counterparts in geomagnetics, are not considered herein.)

We introduced the term "aeolian" not only to describe the non-stationarities but also to specify the steps required for their study with their existing limitations. A first inferential statistical procedure involves global (entire time series-based) tests of the "no-cycle" (zero-amplitude) assumption and thus of the probability that each anticipated spectral peak is the result of chance variation. If rejected, the alternative hypothesis that it represents a cycle is accepted. The rejection of the zero-amplitude assumption leads to parameter estimation, including the derivation of CIs (95\% confidence intervals) for each parameter of the fitted model. In particular, CIs of the periods are useful to assess the extent of similarity of cycles characterizing different variables. So are the CIs of the amplitudes that indicate the prominence of a given component by the distance from zero of the lower limit of its CI. Congruence is defined by the total or partial overlap of CIs of periods of anticipated cycles between two (or more) variables. An overall assessment of congruence over a specific spectral region can also be defined by the proportion (out of the total) of statistically significant spectral peaks with overlapping and/or overlying CIs of their periods. The proportion of similarities is likewise defined by proximal (yet not overlapping) CIs of periods, when the distance between CIs is less than the shortest $\mathrm{CI} / 2$ of the periods involved. These admittedly arbitrary definitions need to be improved as data accumulate and distributions of congruence become available for study by "subtraction and addition" ("remove and replace") approaches. We herein focus on solar wind speed (SWS) and the antipodal geomagnetic index aa, neither the sole nor the most pertinent indices of heliogeomagnetics. The relative merits of different gauges of solarterrestrial-biospheric associations remain to be systematically compared.

Cycles constitute life at all levels of integration, including the atomic level, where they are considered for the case of the origin of about-weekly rhythms (Ulmer et al. 1995). An about 21-hour cycle, among others, characterizes a prokaryote (Halberg and Conner 1961) and about 1-, 3.5- and 7-day cycles, eukaryote single cells (Broda et al. 1986, Cornélissen et al. 1986, Schweiger et al. 1986) and organs such as the human gut (Cornélissen et al. 2002, Hoogerwerf et al. 2007). Somewhat specific and yet many other periods are validated for the heart (Sothern et al. 2009b), the brain (Halberg et al. 2003a) and the health of individuals' body and mind as a whole and for various affairs of populations (Halberg et al. 2008c). Biospheric cycles at their diverse organizational units and frequencies, the topic of chronobiology, resonate with a broad spectrum of terrestrial and extraterrestrial counterparts (Halberg et al. 2000, 2008c), the topic of chronomics (Halberg et al. 2001). Cycles from the environment, near and far, are reciprocal to those in living matter, in the sense of having a roughly corresponding period. In the first place, the cosmos generated the cycles that constitute life. The biosphere slowly returns the favor, adding its societal schedules, often fashioned close to the natural cycles. Transdisciplinary reciprocal periodicity, photic and non-photic, postulated and documented in 1991 (Halberg et al. 1991, 2000, 2001, 2008c) in inferential statistical terms (Halberg 1980, Cornélissen and Halberg 2005, Refinetti et al. 2007), with deterministic chaos and trends, constitute time structures, i.e., chronomes of cosmic effects in the biosphere (Halberg et al. 2001). While the problem has been discussed with great enthusiasm by innumerable others, with notable exceptions, concern about uncertainties associated with the many cycles reported was conspicuous by its absence (Dewey and Mandino 1971). This was a great disservice to the 
field and perhaps the root cause for its neglect. Nonetheless, without an inferential statistical approach, the vast literature on solar- terrestrialbiospheric associations had been scholarly reviewed and summarized in Fig. 1 (shaded part).

Much-written-about cosmic-biospheric interaction is too often descriptively statistical (Dewey and Mandino 1971), based on the inspection of data plotted along scales of time or frequency, interpreted by the unaided eyes, more often than not without estimates of uncertainties. The prefix "quasi" before "periodic" and before "persistent" is a recognition of non-stationarity (Bartels 1959), sufficing neither as an excuse for ignoring tests of a cycle's validity nor for failing to look at uncertainties of its parameters, as a sine qua non for ascertaining the phenomenon's transdisciplinary associations as putative mechanisms involved in important human affairs. Until the ever-present uncertainties as to the reciprocity of periods being considered are determined, subjective inferences as to the correspondence of certain periods are unavoidable. Justified, eloquent inspiration and enthusiasm (Dewey and Mandino 1971) do not dispense with needed probabilistic qualification, recognized by Bartels (1959), and quantification with uncertainties. CIs of the periods often lack even in the most outstanding recent publications by physicists that provide usually only point estimates of the periods, with few exceptions (Yamamoto et al. 2004, Takumi et al. 2006). This status quo, also in biology, has brought the field of solar-terrestrial-biospheric associations into neglect, even disrepute. Much time-macroscopic investigation in the molecular biology of circadian rhythms is published only as time plots of mean values or displays in frequency, that provide neither an opportunity to test the validity of the cycle nor an evaluation of its definition gauged by the CIs of its parameters. Reanalyses and/or meta-analyses of the plotted mean values may not uncover the validity of certain putatively periodic changes until the original data are alsoconsidered (Sothern et al. 2009a).

\section{MATERIALS AND METHODS}

Our approach presumes that any cycles around us, like any cycles in us, have been assessed objectively and quantitatively by generally applicable criteria, even when the computed uncertainties of their characteristics serve only for ordering purposes, as is the case herein. For a test of equality or similarity of periods, their conservative CIs are computed with a method proposed and programmed by the late Marquardt (1963). When Marquardt's conservative CIs are replaced by his one-parameter CIs, this is noted.

While CIs are currently conspicuous by their absence in many contributions of spectra in physics, Marquardt's method is available and provides uncertainties concomitantly for each period as well as for corresponding amplitudes and acrophases (indicating the overall timing of high values occurring in each cycle), and for the MESOR (midlineestimating statistic of rhythm), usually more accurate and more precise than the arithmetic mean. Nonetheless, the results from the application of Marquardt's method to non-stationary cycles have to be qualified. What Marquardt (rightly for stationary time series) designated as conservative CIs may be too liberal when the underlying assumptions are not met, and consequently the same qualification applies to cycle detection by the zero-amplitude test. Hence, as noted above, in the case of non-stationarity, we refer only to ordering statistical significance yielded by his procedure. A further qualification stems from CIs that differ as a function of whether a given cycle is assessed alone or as part of a composite model. ${ }^{1)}$

We use Marquardt's approach, i.a., in studies of congruence ${ }^{2)}$ with these limitations in mind: it allows us to account for noise which we could not do, were we to define congruence as the proportion of equal orderingly statistically significant cycles. It is tempting to do this, since some of the point estimates of periods in series being compared can be identical to the second decimal, but these are the exceptions

\footnotetext{
1) There is another major limitation related to the resolution from the record's length: low-frequency components are more likely to be found congruent because CIs are much wider. Another way to compare the time structures of two time series is to correlate the amplitudes of integer frequencies of their spectra, provided both time series have similar lengths and sampling density.

${ }^{2)}$ Congruence: derived from the Latin prefix “con", meaning "together", while "-gruent" reflects the present participle of putative Latin "gruere". The Latin present participle "congruens" means "agreeing with", "appropriate to", "fitting with". Congruence is defined by the total or partial overlap of CIs of periods of anticipated cycles between two or more variables (or time series). An overall assessment of congruence in two or more time series over a specific spectral range can also be defined by the proportion of periods found by, e.g., the extended cosinor (Halberg 1980, Cornélissen and Halberg 2005, Refinetti et al. 2007) with overlapping, including overlying CIs. Congruence serves to assess the normal cyclic association within or among disciplines, e.g., in certain spectral regions, among others, of various physiologic and other biospheric measurements (SBP or DBP and HR) individually with series of environmental (terrestrial, solar, cosmic) measures. It can thus vary from 0 to $100 \%$. A complete lack of congruence $(0 \%)$ can be described as acongruent, with the prefix "a-" derived from the Greek alpha privative to negate a root word, as in "atom". The previous prefix, "-con-", is here used as an infix. Note that "acongruent" was preferred to "incongruent" because the latter is sometimes found in contexts indicating something bad or abnormal.
} 


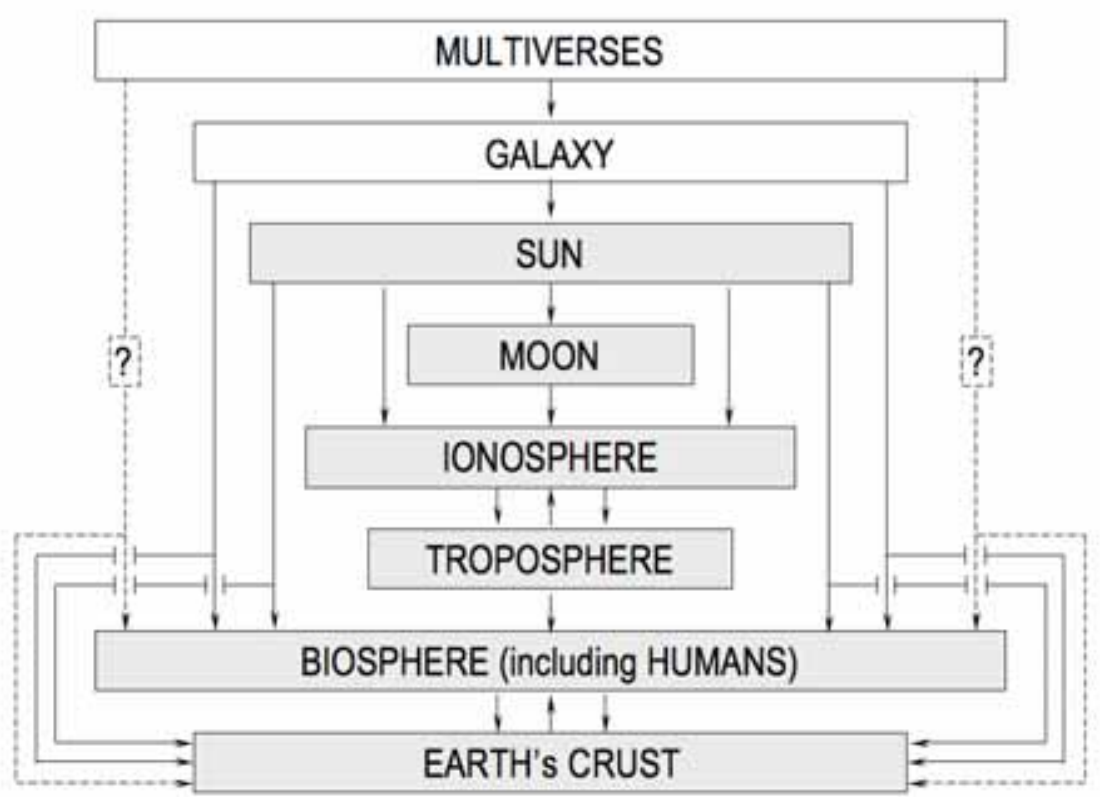

Fig. 1. Overview of solar-terrestrial-biospheric associations compiled from extensive published works.

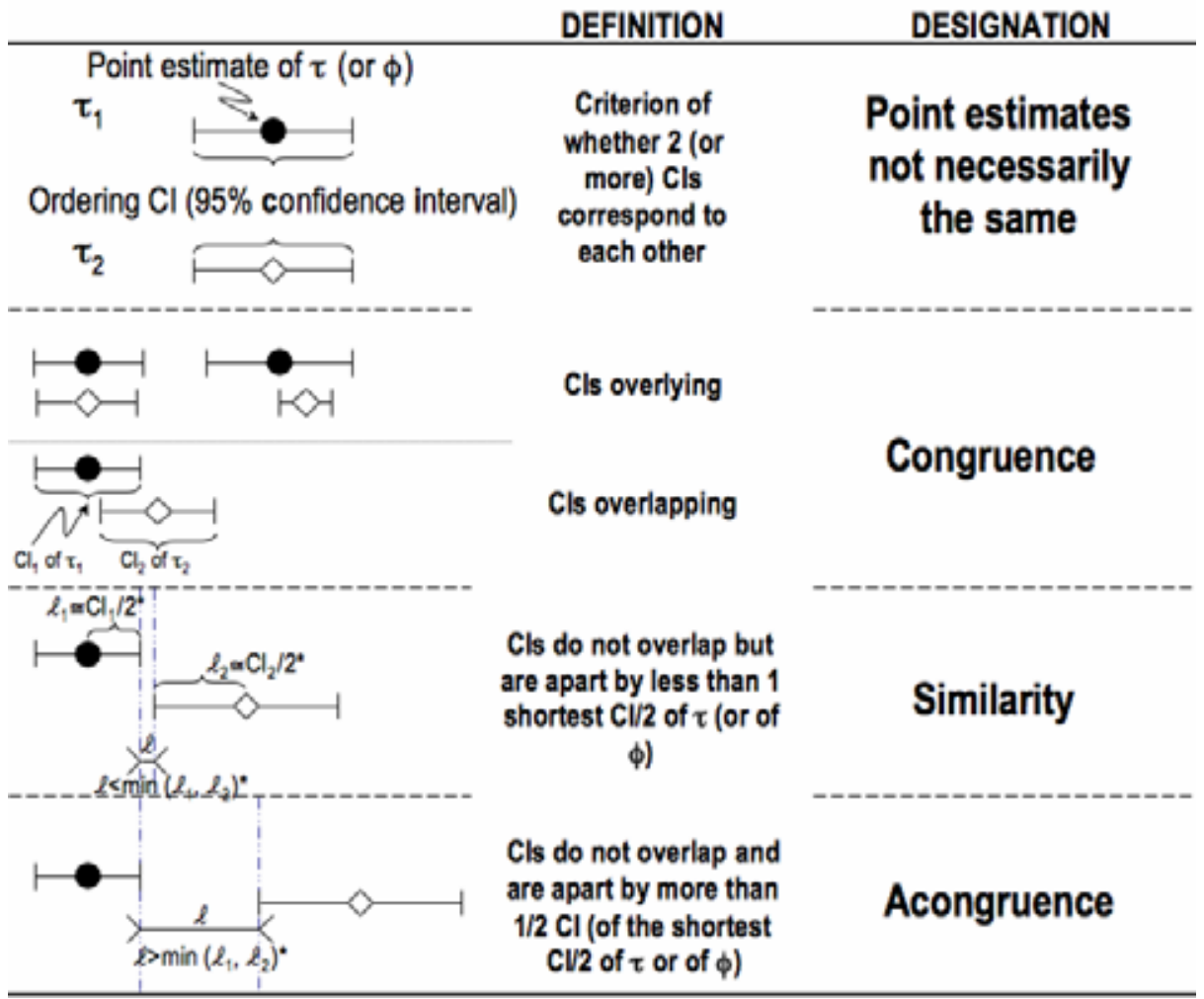

Fig. 2. Two or more variables (or time series) are said to be congruent at a given (anticipated) frequency when the CIs of their periods assessed nonlinearly (with Marquardt's algorithm) are overlapping or overlying. The concept of congruence can be extended to the broader time structure with respect to a specified frequency range by considering the proportion of statistical components in two or more time series of corresponding length with congruent periods. Similarity is defined when the respective CIs are close but non-overlapping, by contrast to acongruence when the CIs of periods are far apart from each other. 
rather than the rule. The alternative is to account for uncertainties estimated as CIs, and to include in the definition of congruence a partial overlay of CIs, Fig. 2. Quite apart from uncertainties assessed by CIs of periods that relate primarily to the record's length, there can also be a fair amount of variability in a cycle's characteristics over time related to its non-stationarity, as revealed in gliding spectra and chronobiologic serial sections (Halberg et al. 2008c).

The SWS data, determined in satellites, were downloaded from http://omniweb.gsfc.nasa.gov and the aa values from:

http://www.geomag.bgs.ac.uk.aaindex.html, serving as a gauge of terrestrial magnetism. The biological data analyzed herein are self-measurements (about 5 per day) from a clinically healthy man (RBS) recorded daily for about 4 decades, while aging from his twenties to about 60 years of age. Variables monitored include oral temperature, heart rate (HR), systolic (S) and diastolic (D) blood pressure (BP), ratings of mood and vigor, and the estimation of 1 minute (1MTE) by counting (Halberg et al. 1972), the latter variable recorded for about 35 years (Halberg et al. 2000, 2008d). Morning BP and body weight measurements by another man (WRB) treated for high BP, started at about 52 years of age for the ensuing 30 years serve for added methodological considerations, as do BP and HR data collected around the clock at 30-minute intervals by two other elderly men treated for MESOR-hypertension (FH and GSK). So do 7-day BP and HR records (with measurements every 30 minutes during waking and 60 minutes by night) from 232 residents of Urausu, Japan, 24-79 years of age (mean \pm SD: $56.8 \pm 11.2$ years).

The data were analyzed by the extended cosinor (Halberg 1980, Cornélissen and Halberg 2005, Refinetti et al. 2007). Results from the latter study were compared by Student t-test between men and women and age trends were assessed by linear regression. Participants were also asked to answer a self-administered questionnaire inquiring about 15 items of a depression scale (geriatric depression screening scale, GDS). Subjects with a score of 5 or more on this scale were considered to have a depressed mood. The circadian period and amplitude of SBP, DBP and HR were linearly regressed with the GDS score and compared by Student t-test between subjects with and without a depressed mood. Testing was at the significance level $2 \alpha=0.05$.

\section{RESULTS}

\section{Wobbliness of environmental and biological variables}

Components in SWS and in the aa index can be extremely wobbly, as seen in Fig. 3A (left, gliding spectra suffice to reveal). ${ }^{3)}$ By contrast, periods such as $0.72[0.71,0.73]$ and $1.06[1.05,1.07]$ year(s) (in global spectra, right) are seemingly identical for SWS (top) and aa (bottom). In these particular cases, when the sampling rate and record length are the same (except for some missing data for SWS, but not aa), not only the period estimates but also their CIs happen to be identical to the second decimal.

Gliding spectra (Fig. 3A, left) suffice to reveal drastic differences in the time structure of SWS and aa. The time structure of both variables further differs from that of a human mental function, RBS' 1MTE, Fig. 3B (bottom). Some similarities with SWS and aa are seen nonetheless, notably a band around an about 1.3-year period from 1985 to 1995 . All three variables are characterized by the lack of a consistent, precise 1-year component, Fig. 3B. Numerical results regarding the periods in global spectra are given in Tables 1 and 2. RBS's circulation (Fig. 3C), with focus on his SBP (Fig. 3D) is characterized by a seemingly dominant calendar year, even though the lower limit of this period does not cover the precise year. With some of the non-stationary variability visualized in the gliding spectra of Figs $3 \mathrm{~A}-\mathrm{D}$, it seems clear that alternative objective methods are needed to complement the CI from a global analysis (of the series as a whole).

\footnotetext{
3) As compared to relative sunspot (Wolf or Zürich) numbers, the solar wind is a more recent and hence shorter time series among the gauges of solar activity that became available in the satellite age, discovered by the Soviet Luna 1, 2 and 3 and confirmed by Mariner 2. Along with a few heavier ions, a roughly equal number of electrons and protons blow continuously from the surface of the sun at a speed averaging $400 \mathrm{~km} / \mathrm{s}$ but changing with predictable patterns, analyzable among other characteristics, as solar wind speed (SWS). These high-speed charged particles constantly blowing off the sun may be viewed as an extension of the outer solar atmosphere (the corona) into interplanetary space. The global terrestrial index of magnetic activity aa is produced in France from the $\mathrm{K}$ indices of two nearly antipodal magnetic observatories in England and Australia. This index has been extended from the present back in time to 1868 through scaling of magnetic activity from magnetograms of available dated observations. Some features of a spectra show remarkable agreement with those of the SWS. Study of the aa index, SWS and of biospheric variables has revealed, among many other very wobbly components, near-transyears, longer than a calendar year but shorter than 1.2 years $(1.00$ year $<[\tau-\mathrm{CI}]<[\tau+\mathrm{CI}]<1.2$ years, where $\tau$ represents the period estimate $)$ as well as far-transyears $(1.2$ years $<[\tau-\mathrm{CI}]$ $<[\tau+\mathrm{CI}]<1.9$ years). These spectral regions are defined broadly since they characterize not only the non-stationary behavior of SWS and aa, but the drifting frequencies (to the point of bifurcating, disappearing and reappearing) and waxing and waning amplitudes also mirrored in the biosphere. (Partly adapted from csep10.phys.utk.edu/astr162/lect/sun/sind.html and www.ngdc.noaa.gov/stp/GEOMAG/aastar.shtml)
} 

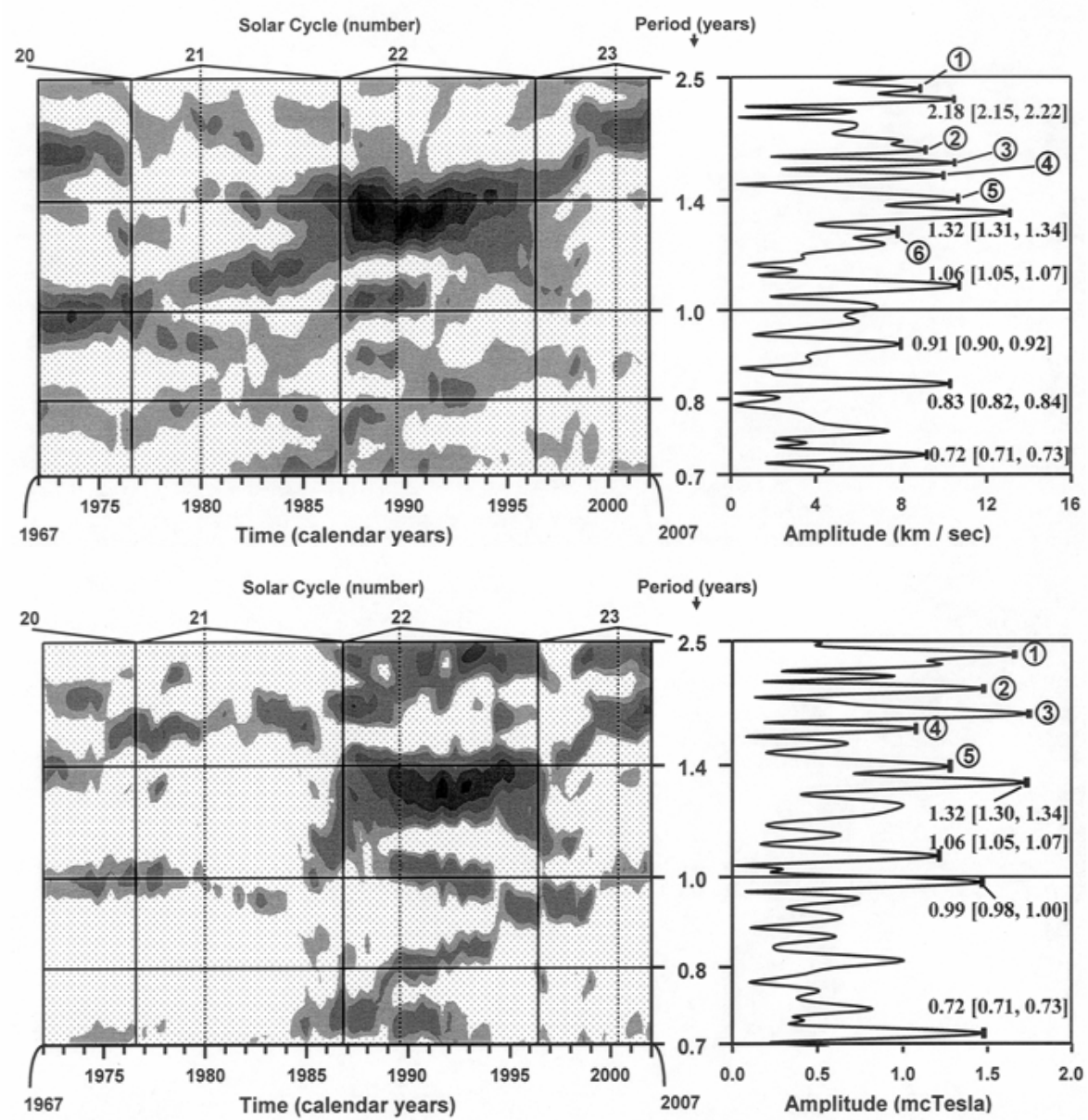

Fig. 3A. A few identical-seeming periods in solar wind speed (top) and geomagnetism (bottom) in global summaries (right) are qualified by their differences in their time course, seen in gliding spectral windows (left).

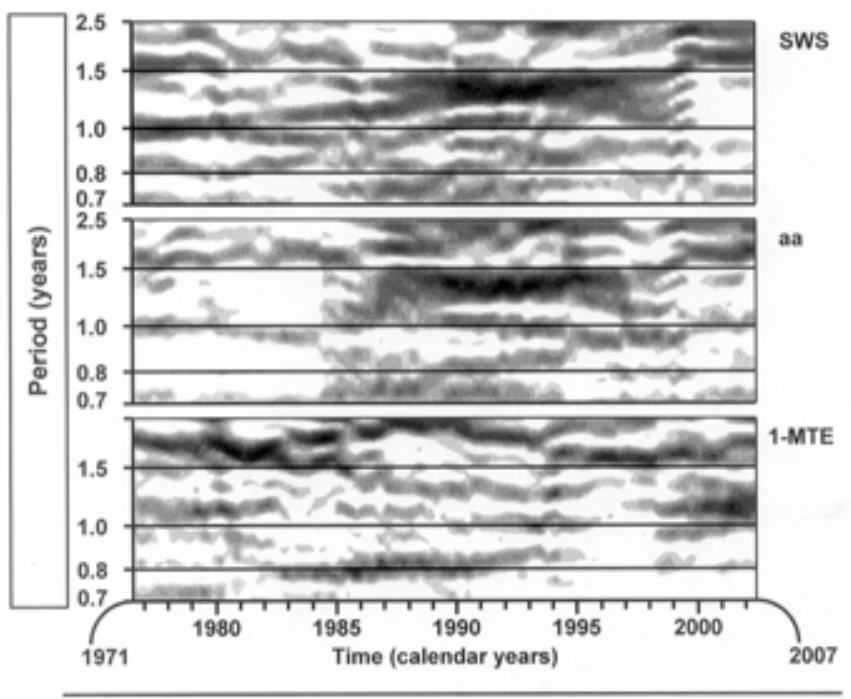

Fig. 3B. Aeolian time course of a human mental function (bottom) aligned with solar wind speed (top) and geomagnetism (middle) reveals a thinner band around a period of 1.3 years (ordinate) after 1986, corresponding to the thick black bands in helio-geomagnetics (top and middle). 


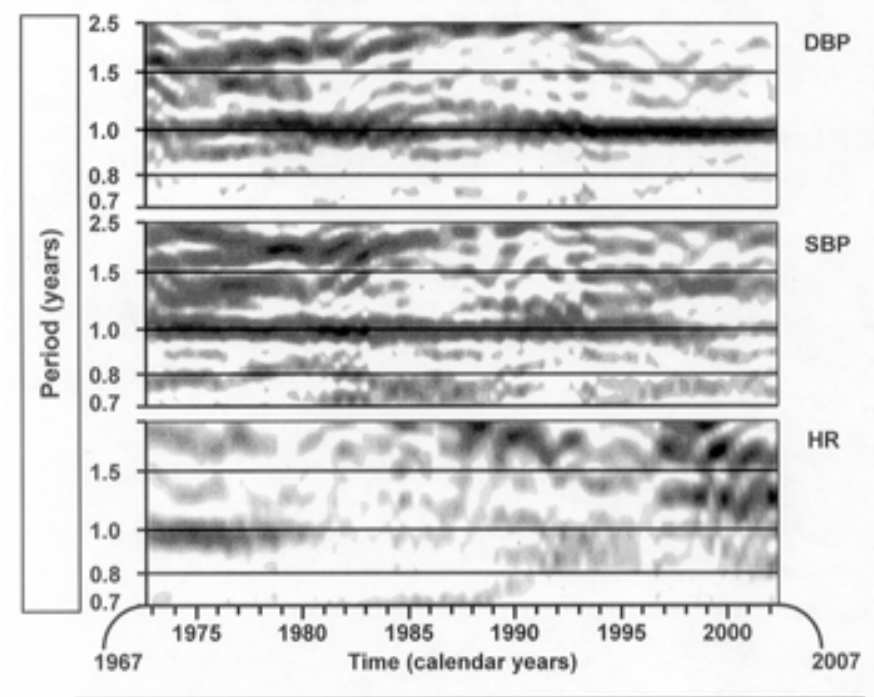

Fig. 3C. Aeolian time course of diastolic blood pressure (DBP; top), systolic blood pressure (SBP; middle) and heart rate (HR; bottom) of a clinically healthy man (RBS) monitored over 4 decades. Note components with waxing and waning darkness (amplitude, A) and drifting or even disappearing period (white) resembling or perhaps rather corresponding in kind to the images of helio- and geomagnetic patterns in Fig. 3B.
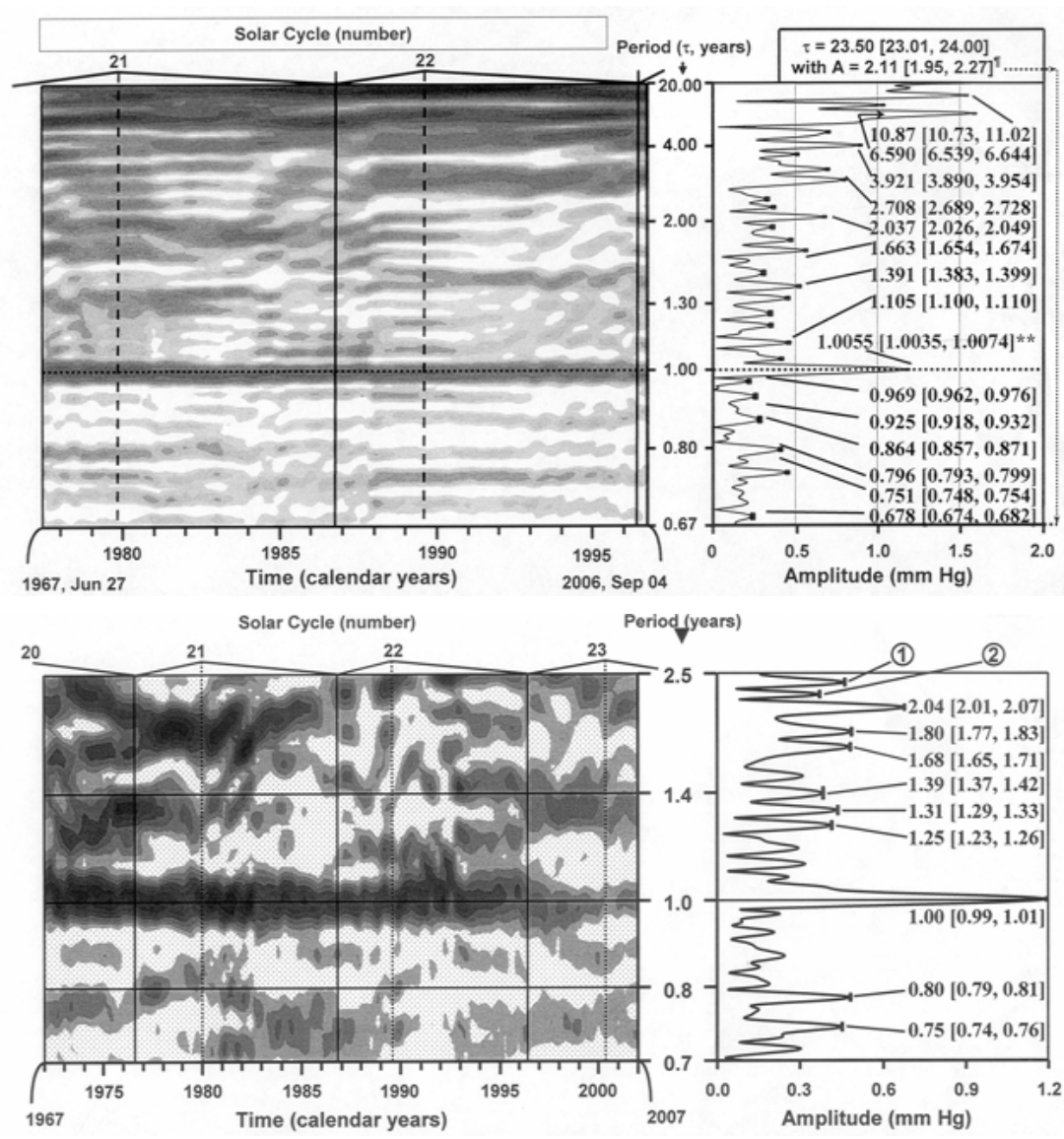

Fig. 3D. Dominance of about 1-year synchronized component in RBS's SBP, yet with coexisting far-transyear component, with a period of about 1.3 years. In another model, the exact numerical estimate of the period deviated from a precise calendar year in the third and fourth decimal place as 1.0055, with a CI extending from 1.0035 to 1.0074, prompting Fig. 3E. 


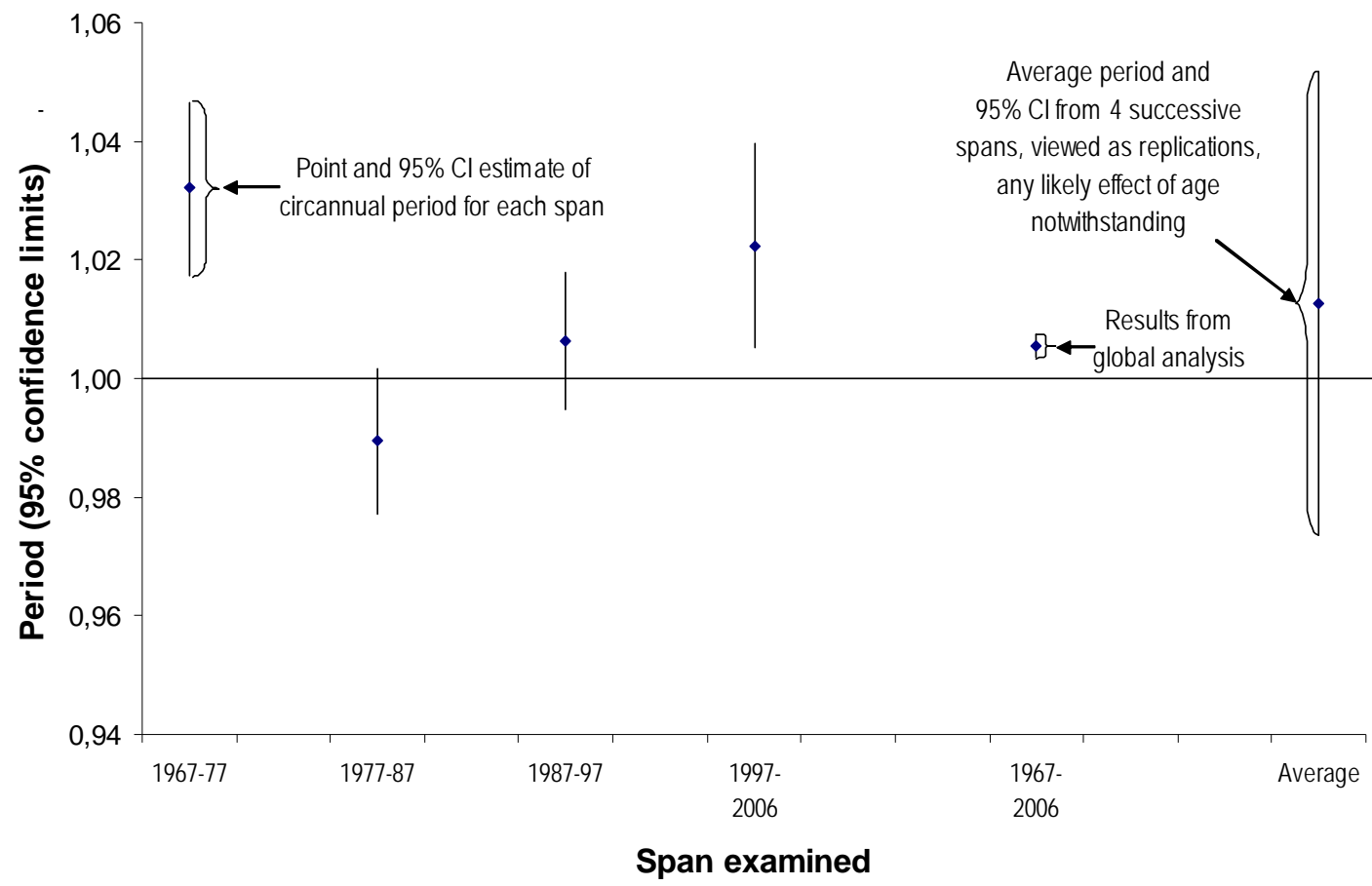

Fig. 3E. Different uncertainties for one of the estimates of a time series, computed, on the one hand, globally by the conservative method of Marquardt (1963) or, on the other hand, by the summary of estimates derived from the analysis of 4 sections of the same time series for the SBP of RBS. The impression from the global analysis (horizontal arrow) of a desynchronized yearly rhythm is not supported by the summary of two of the decadal sections whose CIs of the period overlap the precise year, as does the $\mathrm{CI}$ of the average (oblique arrow).

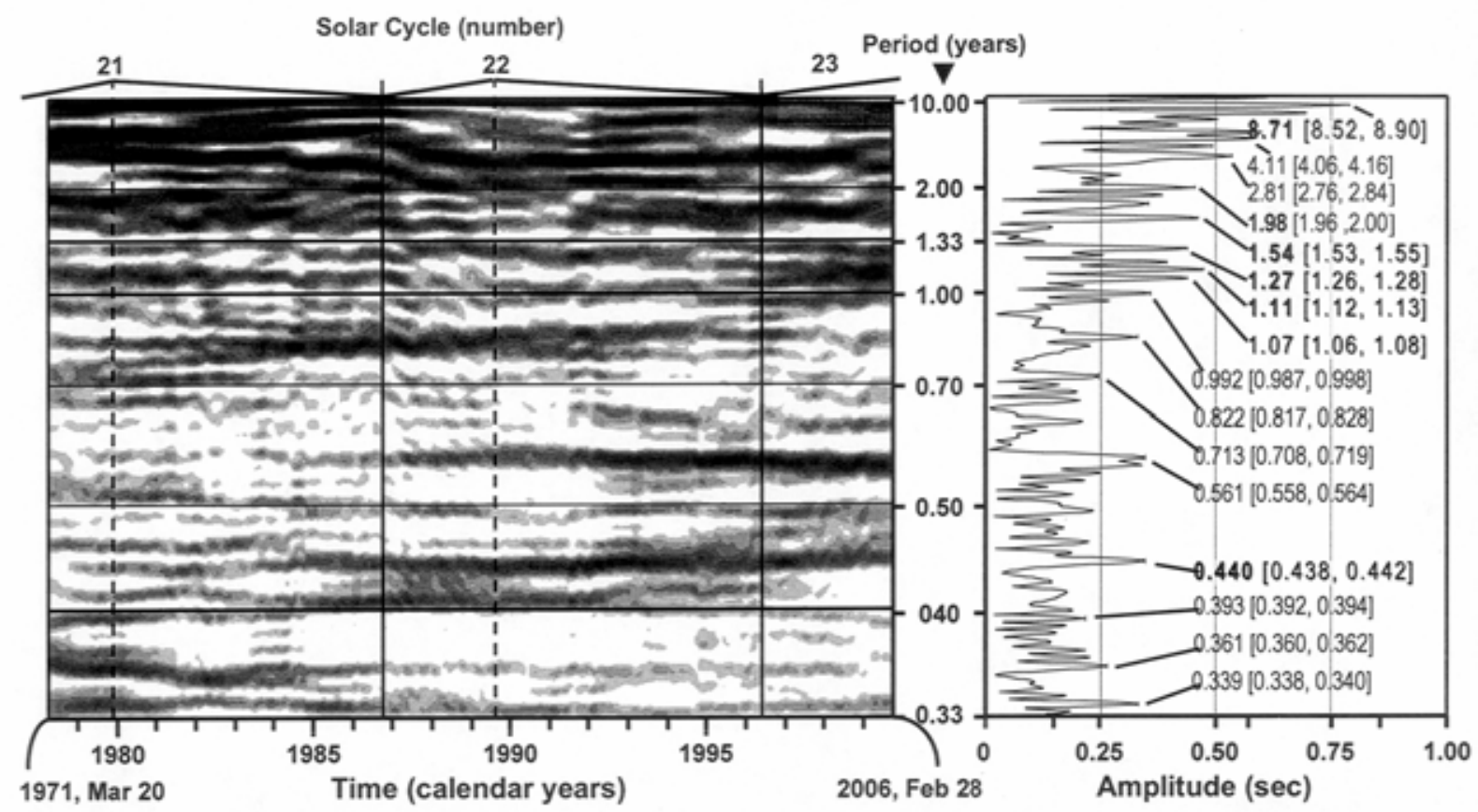

Fig. 3F. Several near-transyears and far-transyears, and cis- (on this side of, i.e., shorter than) years and trans-half-years in RBS's 1MTE are very wobbly, with drifting frequencies in us, as seen in Figs 3B-3D, and around us, Fig. 3A. 


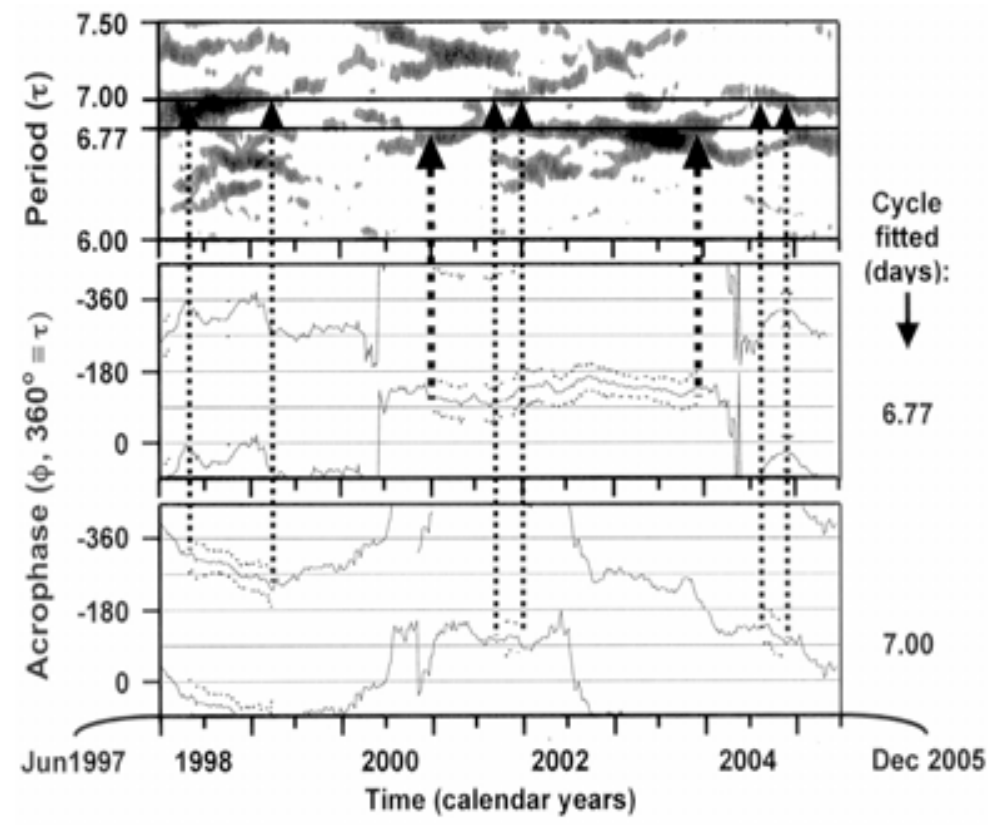

Fig. 4A. Behavior of two selected components of SWS with trial periods of 7.00 and 6.77 days in a gliding spectral window (top), plotting the percentage rhythm (proportion of variance accounted for by fitted cosine curve of given frequency in specified interval) as it changes with time in the circaseptan spectral window investigated. The darker the shading, the more prominent is the signal. Acrophase windows of two chronomic serial sections (middle and bottom) focus on the 6.77-day and 7.0-day components. The former is statistically significant for only part of the record by a horizontal time course of the acrophases (bracketed by dots). The precise 7-day cosine fit has only a few dots bracketing a horizontal time course of acrophases, whereas an initial section with dots shows a gradual advance. These results in the bottom two rows detect the anticipated 6.77-day but no precise consistent weekly component in helio-geomagnetics.

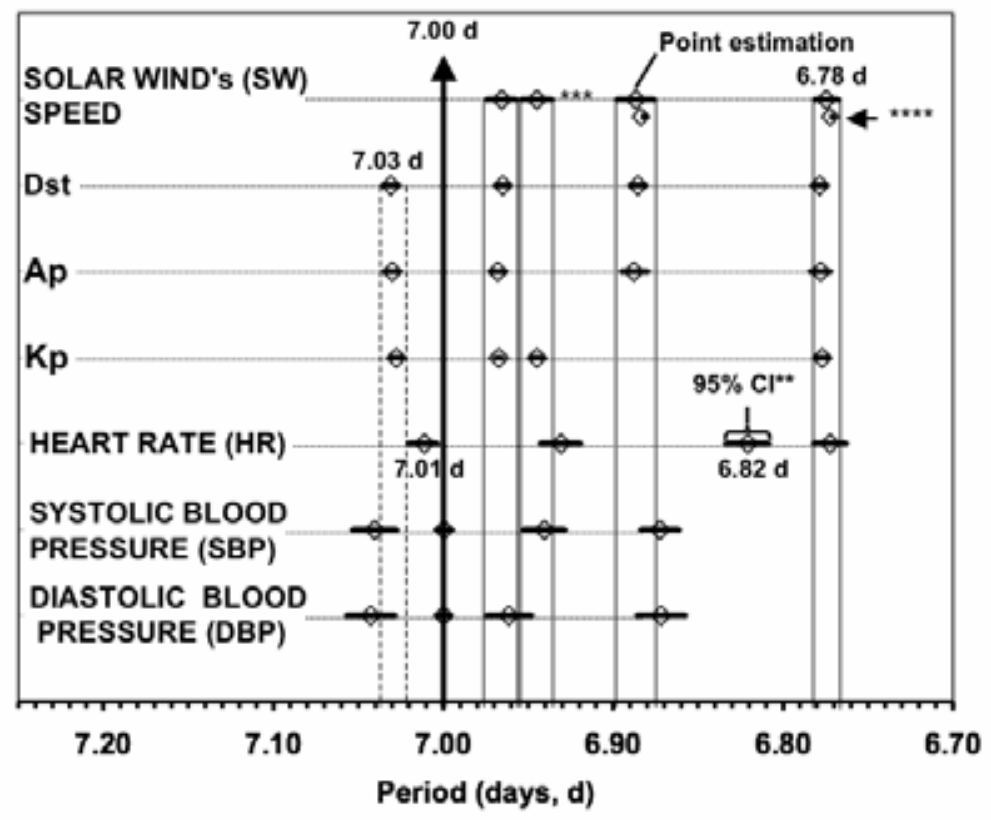

Fig. 4B. Transdisciplinary selective congruence in the 7-day spectral region in GSK's data, assessed in relation to Dst (Equatorial geomagnetic index), Ap (averaged planetary A index based on data from a set of specific Kp stations) and Kp (Planetary geomagnetic index). 


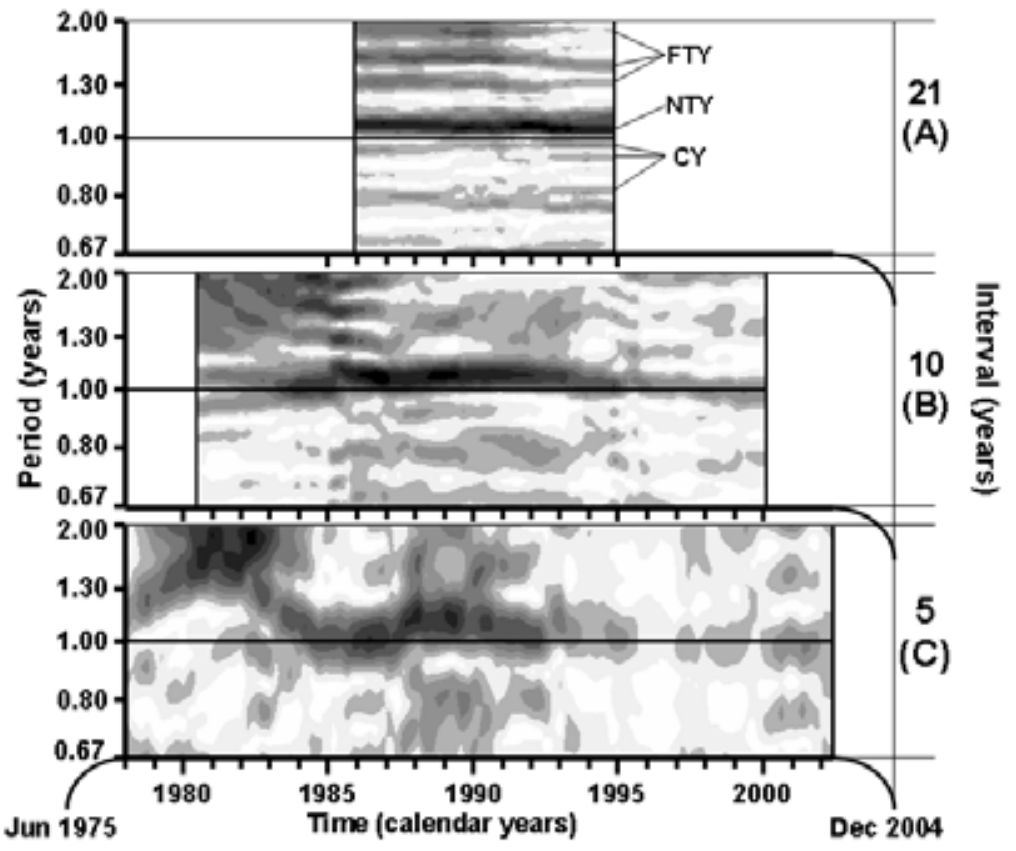

Fig. 4C. Time course of components with different frequencies resolved in terrestrially telescopically assessed solar magnetism by analyses with three complementary interval lengths, revealing that various components seen with a long interval of 21 years (top) undergo changes in a broad frequency band as a function of time, seen with shorter intervals of 10 (middle) or 5 (bottom) years.

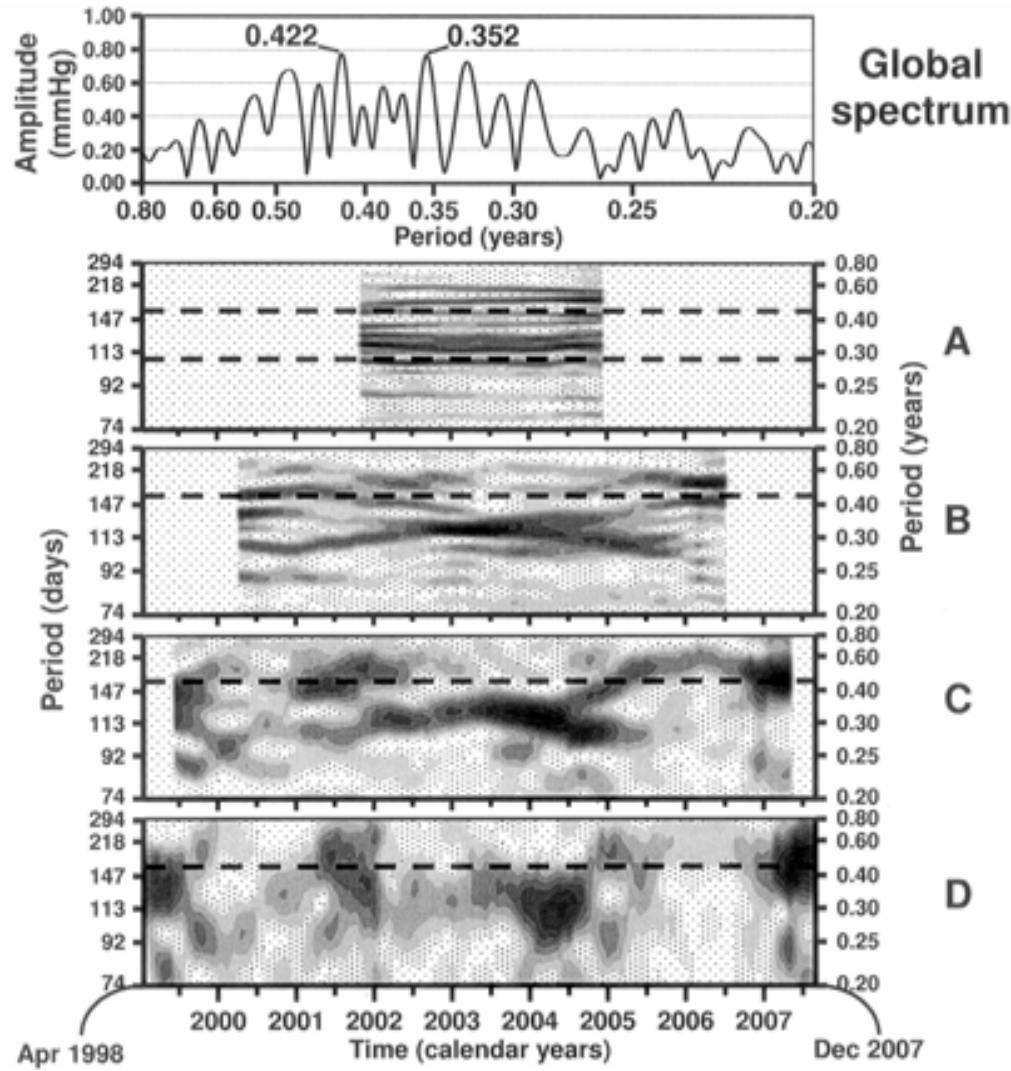

Fig. 4D. Global spectral window (top) with focus on the cis-half-year range of diastolic blood pressure of GSK resolved with four different interval lengths, revealing a greater variability in time, the shorter the interval length. 
One alternate method is to compute the average variabilities encountered in sections of the series, Fig. 3E. As compared to the tight CIs from global analyses (horizontal arrows), uncertainties are much wider when results from different sections of a time series are averaged (oblique arrow). The decision as to how many sections are to be made of any available time series is subjective, yet use of the sections-based approach qualifies the global estimate and prevents premature extrapolation as to whether the circannual rhythm in SBP is desynchronized or synchronized by the calendar year. The circannual component in RBS's SBP is seen overall to be synchronized with the calendar year by the sections-based method, Fig. 3E.

A near-transyear $(1.00$ year $<[\tau-\mathrm{CI}]<[\tau+\mathrm{CI}]$ $<1.20$ years, where $\tau$ is the period estimate) of 1.07-year length for 1MTE differs from precisely 1 year, and the CI of its global period [1.06, 1.08 years] overlaps the CIs of periods [1.05, 1.07 years] in SWS and aa (see Fig. 3A and 3F). This transdisciplinary mutual validation of a human mental function's congruence with very similar periods in SWS and aa (Fig. 3A), or vice versa, could be happenstance, yet it warrants further investigation. When, numerically, congruence at more frequencies are found between a human mental function and SWS than between SWS and aa, Table 1, the result gains in interest. In any event, a remove-and-replace approach deserves implementation. These associations by congruence relate to important aspects of personal and societal health.

\section{Aeolians}

Many non-photic infradian spectral components in the environmental and biospheric aspects of a transdisciplinary spectrum reveal non-stationarity to the point of intermittency, as illustrated in Figs 3A-D. In keeping with an international interdisciplinary consensus (Chibisov 2005), these irregular, sometimes intermittent cycles, waxing and waning in amplitude, drifting, bifurcating, disappearing and rejoining in frequency, with or without changes in waveform, quantified by harmonics of fundamental periods, are dubbed aeolian, after Aeolus, the capricious ruler of the winds, rather than quasi-periodic, if and only if their behavior described in the foregoing is brought into view by analyses done concomitantly, globally, in spectral windows of the series as a whole, and temporally, e.g., in gliding spectra and/or in chronomic serial sections, the latter displaying parameters like the period, amplitude, acrophase and MESOR as a function of time, with all parameters, global or serial-sectional, provided with their uncertainties.
Fig. 4A combines a gliding spectral window (top) of SWS with plots, part of serial sections with trial periods of 6.77 (middle) and 7.0 (bottom) days, showing that a non-social geomagnetic (Halberg et al. 1991, Roederer 1995, Vladimirskii et al. 1995) component of 6.77 days is statistically significant for about half of the record length, as seen by CIs shown as dots bracketing the horizontal section of 6.77-day acrophases (middle row). By contrast, the fit of a 7.0-day societal component shows no stable horizontal time course (Fig. 4A, bottom row). When it is statistically significant (e.g., initially, while bracketed by dots), the phases advance, indicating a period shorter than 7.0 days. Aeolian cycles are thus seen to drift in period, to the point that they are no longer detectable with statistical significance, be this because they are buried in noise or actually disappear to be re-excited subsequently. These nonstationarities apply in particular to cycles in particle radiation from the sun or from elsewhere, broadly to galactic-, solar-, interplanetary-, ionospheric- and geo-magnetics, UV flux, gravity and all other non-photic measurable environmental cycles, briefly to non-photics. Many factors, beyond our scope herein, contribute to these non-stationarities that are in sharp contrast with changes associated with the visible range of the electromagnetic spectrum, such as with the day and the seasons that are usually less irregular.

The term "quasi-periodicity" is here restricted to describing a lack of inferential statistical considerations, e.g., a lack of attempt to test the cycle's validity and/or the failure of seeking estimates of uncertainties of the parameters of the cycle. This testing complements the time-macroscopic data display in gliding spectral windows of Fig. 4A. Fig. 4B provides a chart of about 7-day components showing differential congruences. Congruences are selective in that they differ for the BP versus HR of the same subject (GSK), a man receiving anti-hypertensive medication. There is congruence of HR but not BP at a 6.78-day period with both SWS and three geomagnetic indices, while at other periods, helio- and/or geomagnetics are congruent only with BP, Fig. 4B.

In viewing gliding spectra, e.g., of the solar magnetic field, a good resolution is obtained in the frequency domain by the use of a long 21-year interval (Fig. 4C, top). To gain resolution in the time domain, these results can be complemented by the use of shorter (e.g., 5-year) intervals (Fig. 4C, bottom). An intermediate interval of 10 years offers a perspective in both time and frequency (Fig. 4C, middle). Whereas a frequency band shows a component with a period slightly but clearly longer 
Table 1. Periods of helio-geomagnetics (columns 2 and 3), congruent* with each other or with a mental function (the estimation of 1-minute) by a healthy man (RBS) over 3.5 decades (column 4) or terrorism (bottom, bold).

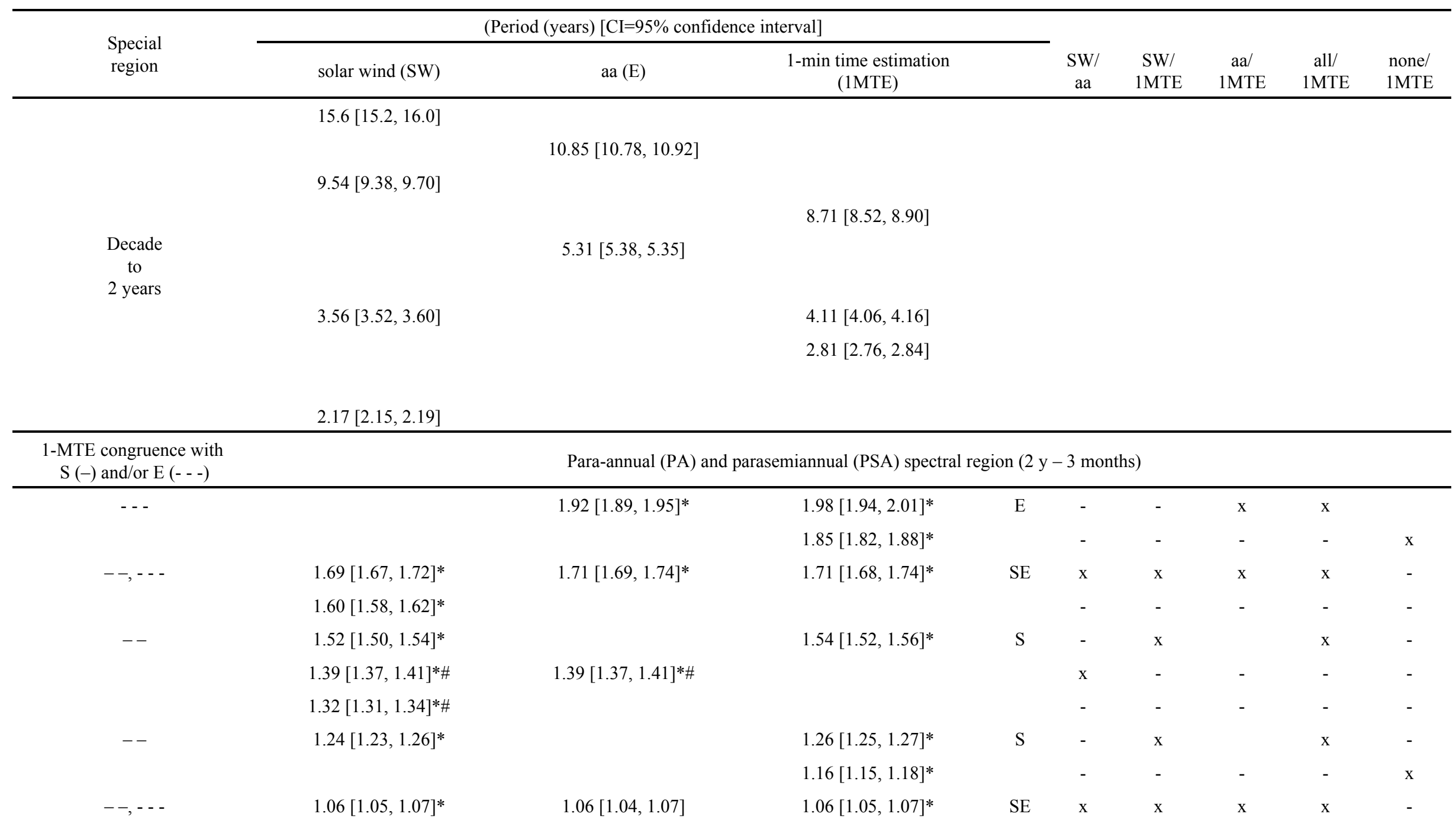


- - -

$0.91[0.90,0.92]^{*}$

$0.83[0.82,0.84]^{*}$

$0.72[0.71,0.73]^{*}$

$0.559[0.557,0.561]$

$--$

$0.524[0.522,0.526]$

$0.500[0.499,0.501]$

$-$
$0.99[0.98,1.01]^{*}$

$0.72[0.71,0.73]^{*}$

$0.599[0.598,0.600]$

$0.548[0.547,0.549]$

$0.500[0.499,0.501]$

$0.437[0.436,0.438]$

0.485 [0.483, 0.487]

0.425 [0.423, 0.427]

0.409 [0.407, 0.411]

0.355 [0.354, 0.356]
$0.99[0.98,1.01]^{*}$

$0.82[0.81,0.83]^{*}$

$0.713[0.708,0.719]$

$0.561[0.558,0.564]$

$0.440[0.438,0.442]$

$0.339[0.338,0.340]$
E

$\mathrm{S}$

SE

$\mathrm{x}$

E

$-$

$-$

$-$

$\underline{\mathrm{E}}$

* Totals based on weekly, otherwise on daily measurements. Congruence defined by overlying or overlapping $95 \%$ confidence intervals, given in [ ]. Congruence in column 5 is designated as pertaining to the Sun $(\mathrm{S},--)$ or Earth $(\mathrm{E},---)$, as also seen in column 1. For solar sources of geomagnetic activity indicating solar wind, see Space Physics 105:18203-18213, 2000.

\# The transyear of 1.34 years, with CI [1.31, 1.37] of terrorism worldwide is congruent with these environmental periods and time courses show similarities that are resolved with hypothesis testing and estimation elsewhere of the uncertainty of the acrophase. When more data on terrorism are analyzed, the transyear period is of 1.28 [1.26-1.29] years overlapping with a period of 1.26 years in 1-minute estimation and solar wind speed. It is emphasized that the estimation of 1 minute is analyzed here as a gauge of the speed of the passage of time. For assessing the accuracy of performance, the time series will have to be transformed into durations from precisely 60 seconds.

5 out of $21 \mathrm{SW}$ peaks have aa counterparts $(23.81 \%)$

6 out of 21 SW peaks have 1MTE counterparts $(28.57 \%)$

7 out of 16 1MTE peaks have aa counterparts $(43.75 \%)$

7 out of 16 1MTE peaks have SW counterparts $(43.75 \%)$

7 out of $13 \mathrm{~S}+\mathrm{E}$ peaks have $1 \mathrm{MTE}$ counterparts $(53.85 \%)$

7 out of 13 aa peaks have 1 MTE counterparts $(53.85 \%)$

11 out of 16 1MTE peaks have S and/or E counterparts $(68.75 \%)$

2 out of 16 1MTE peaks have neither aa nor SW counterparts (12.50\%)

Terrorism data from: http://www.terrorisminfo.mipt.org/incidentcalendar.asp, accessed October 2007. 
Table 2. Congruent* periods of 7 variables in a healthy man over 4 decades with the solar wind's speed (S) and/or geomagnetism (E).

\begin{tabular}{|c|c|c|c|c|c|c|c|c|c|c|c|c|c|}
\hline Mood estimation & & Vigor estimation & & Systolic BP & & Diastolic BP & & Heart rate & & Oral temp & & Terrorism & \\
\hline \multirow[t]{3}{*}{$2.34[2.28,2.42]$} & & & & $2.35[2.30,2.40]$ & & $2.46[2.42,2.51]$ & & & & $2.41[2.36,2.46]$ & & & \\
\hline & & & & $2.19[2.15,2.24]$ & $\mathrm{S}$ & & & & & $2.19[2.16,2.23]$ & $\mathrm{S}$ & & \\
\hline & & $2.09[2.05,2.14]$ & & $2.04[2.01,2.07]$ & & $2.03[1.99,2.08]$ & & & & $2.06[2.03,2.08]$ & & & \\
\hline \multirow[t]{2}{*}{$1.91[1.87,1.95]$} & $\mathrm{E}$ & & & & & & & $1.86[1.81,1.80]$ & & & & & \\
\hline & & & & $1.80[1.77,1.83]$ & & $1.79[1.77,1.83]$ & & & & & & & \\
\hline $1.74[1.71,1.77]$ & SE & $1.71[1.68,1.74]$ & SE & $1.68[1.65,1.71]$ & SE & $1.70[1.67,1.83]$ & SE & & & & & & \\
\hline $1.64[1.61,1.66]$ & SE & & & & & & & & & & & & \\
\hline $1.51[1.48,1.53]$ & $\mathrm{S}$ & & & & & & & & & & & & \\
\hline \multirow[t]{2}{*}{$1.38[1.36,1.40]$} & SE & & & $1.39[1.37,1.42]$ & SE & & & $1.39[1.37,1.41]$ & SE & & & & \\
\hline & & & & $1.31[1.29,1.33]$ & SE & & & & & & & $1.34[1.32,1.37]^{* *}$ & $\mathrm{~S}$ \\
\hline \multirow[t]{3}{*}{$1.22[1.20,1.24]$} & SE & $1.23[1.21,1.25]$ & $\mathrm{S}$ & $1.25[1.23,1.26]$ & $\mathrm{S}$ & & & $1.25[1.23,1.27]$ & $\mathrm{S}$ & & & & \\
\hline & & & & & & & & & & $1.13[1.12,1.14]$ & & & \\
\hline & & & & & & & & $1.19[1.18,1.20]$ & & & & & \\
\hline \multirow[t]{2}{*}{$1.02[1.01,1.03]$} & & $1.03[1.02,1.04]$ & $\mathrm{SE}$ & & & & & & & $1.09[1.08,1.10]$ & $\mathrm{SE}$ & & \\
\hline & & & & $1.00[0.99,1.01]$ & & $1.01[1.00,1.02]$ & & & & $1.01[1.00,1.02]$ & & & \\
\hline \multirow[t]{8}{*}{$0.99[0.98,1.00]$} & SE & $0.98[0.97,0.99]$ & SE & & & & & $0.99[0.98,1.00]$ & $\mathrm{SE}$ & $0.98[0.97,0.99]$ & SE & & \\
\hline & & & & & & $0.95[0.94,0.96]$ & & $0.96[0.95,0.97]$ & & $0.95[0.94,0.96]$ & & & \\
\hline & & & & & & & & & & $0.93[0.92,0.94]$ & & & \\
\hline & & & & & & & & $0.91[0.90,0.92]$ & & $0.90[0.89,0.91]$ & & & \\
\hline & & $0.82[0.81,0.83]$ & $\mathrm{S}$ & & & & & & & & & & \\
\hline & & $0.80[0.79,0.81]$ & & $0.80[0.79,0.81]$ & & & & & & & & & \\
\hline & & $0.78[0.77,0.79]$ & & & & $0.79[0.78,0.80]$ & & & & & & & \\
\hline & & & & $0.75[0.74,0.76]$ & & & & & & & & & \\
\hline
\end{tabular}

* Congruence defined by overlying or overlapping CIs, given in [ ] ** Assessed jointly with circadidecadal cycle with period of 26.65 years [23.47, 29.83]. 


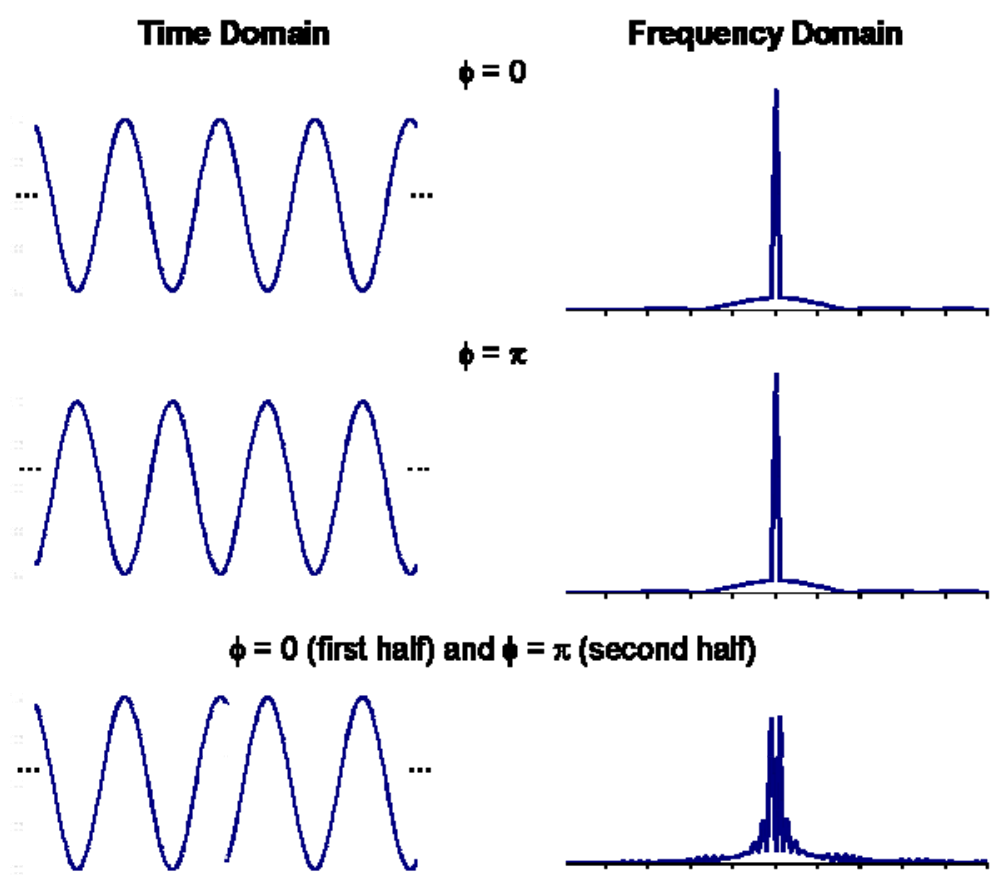

Fig. 5A. Abstract cosine curves with opposite phases (top and middle, left) are characterized by single spectral peaks. Joining the two curves results in a phase jump of $180^{\circ}$ (bottom left). The corresponding spectrum no longer shows a single peak, but rather two major peaks and several other smaller peaks (bottom).

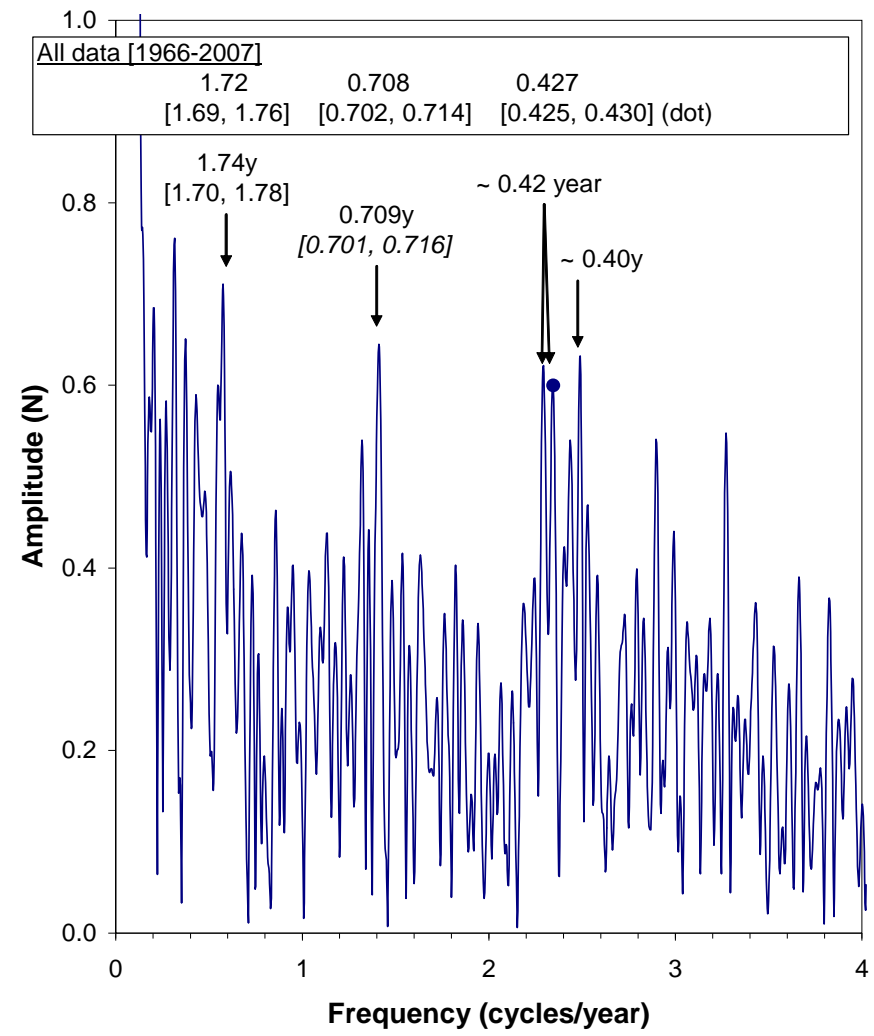

Fig. 5B. Multiple peaklets in the trans- and cis-year and cis-half-year range of the spectrum of solar flares. $\mathrm{N}=\mathrm{N}$ of flares. 

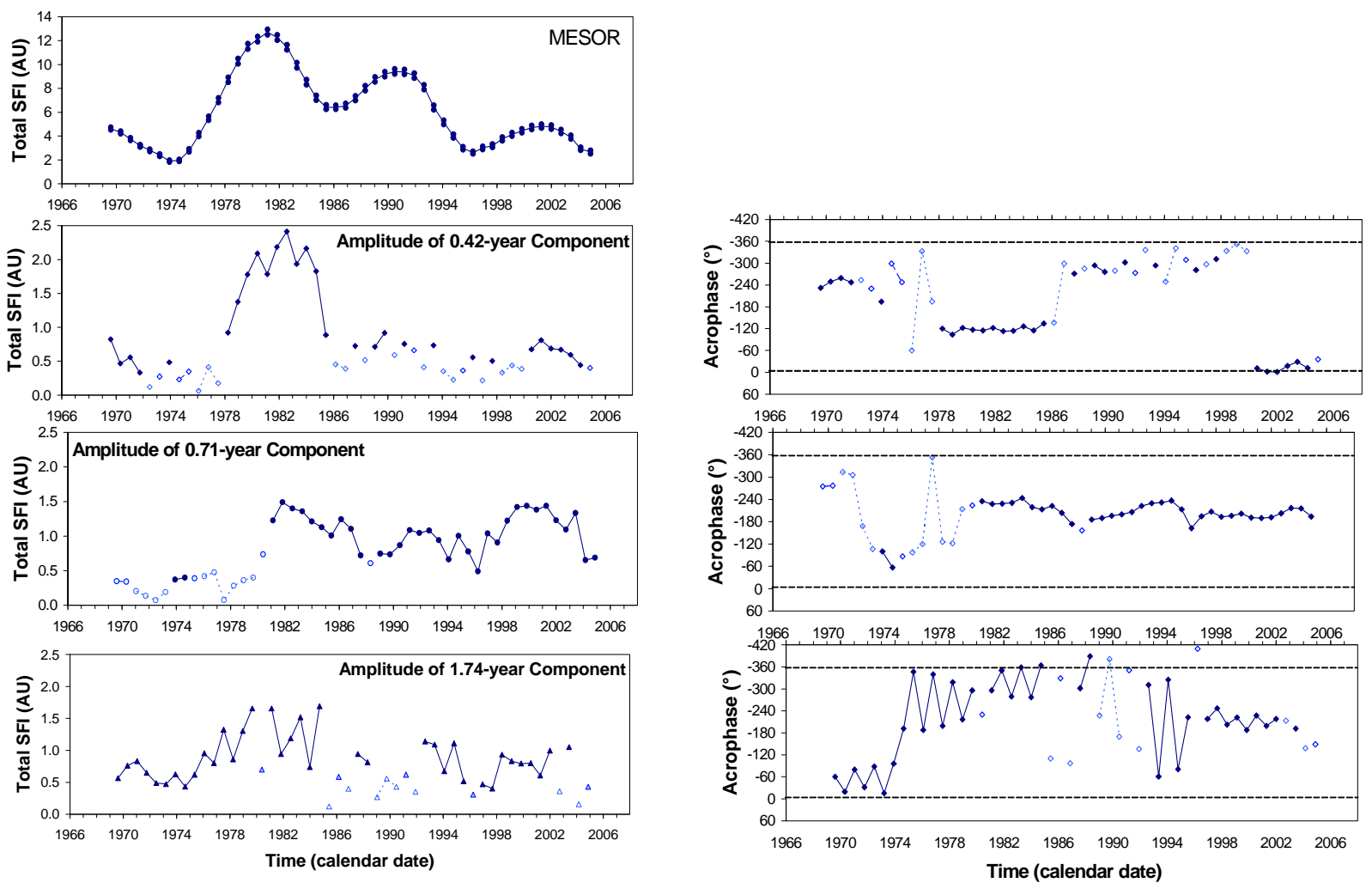

Fig. 5C. The time course of three of the spectral components detected in Fig. 5B is seen to undergo changes in amplitude to the point that statistical significance is lost (open symbols; rows $2-4$, left), and jumps in phase (right).

than precisely 1 year with a 21 -year interval (top), this near-transyear appears to be more prominent toward the middle of the record (middle) and may even be intermittent (bottom).

A cis-half-year of about 0.42 year is found in the DBP of a man (GSK), Fig. 4D. With an interval of 6.4 years chosen, a well-defined frequency is readily apparent (row 2). As the interval for analyses is shortened, changes as a function of time are readily seen in the prominence of this component (Fig. 4D, rows 3-5).

\section{Comparison of spectral domains}

Overdue procedural considerations, as a prerequisite for rules of behavior, are here presented based on inferential statistical methods that are themselves a mere beginning in a temporal microscopy and telescopy (Halberg 1980, Halberg et al. 2000, 2001, 2008c) that found similarities and differences among circadian and extra-circadian rhythms. Circadian cycles in the biosphere are much more often than not synchronized with a 24-hour environmental period. Thus, with Dr. Otsuka, a circadian rhythm could be demonstrated with statistical significance in most adult subjects in Urausu (SBP: $215 / 232=92.7 \%$, DBP: 196/232=84.5\%, HR: 215/232=92.7\%).

The CI of the period covered 24 hours in most cases, in keeping with the anticipated synchronization of the circadian system with the environmental 24-hour cycle. Only 17 (7.3\%) of the SBP periods differed from 24 hours. The periods of DBP and HR differed from 24 hours in $13(5.6 \%)$ and 19 (8.2\%) cases, respectively. The estimated circadian period of BP or HR did not differ between men and women. Men had a statistically significantly larger circadian amplitude of SBP (13.7 vs. $11.1 \mathrm{mmHg}$ ) and DBP (9.0 vs. $7.2 \mathrm{mmHg}$ ) than women. Accordingly, the width of the CI of the period and amplitude was statistically significantly narrower for men than for women. No such gender difference was found for HR. No statistically significant change in the circadian period of BP or HR was found as a function of age, in 
an overall analysis, or in analyses carried out separately for men or women.

The circadian amplitude of SBP decreased as a function of age. This decrease was statistically significant overall $(\mathrm{r}=-0.176)$ and for women $(\mathrm{r}=$ -0.202 ) but not for men. In the case of DBP, the decrease with age was invariably statistically significant (overall: $r=-0.277$; women: $r=-0.316$; men: $r=-0.220)$. Consequently, the relative width of the CI of the circadian amplitude of SBP and DBP increased with age with statistical significance. No statistically significant change with age was found for the circadian amplitude of HR or for the width of its CI. Whereas no difference in circadian period or amplitude is found between subjects with or without a depressed mood for SBP or DBP, in the case of HR, subjects with a depressed mood have a statistically significantly longer circadian period ( 24.25 vs. 23.97 hours). The circadian period of HR is also found to increase with an increasing GDS score $(r=0.189)$ and the circadian amplitude of HR is found to decrease with an increasing GDS score $(\mathrm{r}=-0.163)$.

Infradians $(\tau>28$ hours), like ultradians $(\tau<20$ hours) in the biosphere are often not tightly frequency-synchronized by environmental cycles. Vastly different periods show a high degree of generality, and are important, tipping the scale between death and survival (Cornélissen and Halberg 1994, Halberg et al. 2006). It is important to remember that their periods can be non-stationary, changing with time and hence requiring, whenever the length of a time series permits, as noted, both a global and a temporal analysis, the latter by gliding spectral windows, to track the time course of periods and to proceed with serial sections at each fixed frequency of interest.

There is a need to correctly interpret the presence of multiple spectral peaks that do not invariably reflect the presence of several components, with frequencies matching the spectral peaks. For instance, a jump in phase in the time domain can also account for multiple spectral peaks, as documented by simulations, Fig. 5A. A monochromatic signal with a phase of $0^{\circ}$ or $180^{\circ}$ is associated with a single spectral peak (top and middle). When the time courses are juxtaposed, creating a phase jump, the spectrum of the resulting time series exhibits multiple peaks (bottom row). Concrete multiple peaks are observed in the spectrum of solar flares around 0.42 and 0.40 year, Fig. 5B. They may perhaps correspond to the phase jumps seen in the time course of the cis-half-year acrophases of the same data (Fig. 5C, top row, right). This cis-half-year is also present in the incidence pattern of human sudden cardiac death (Halberg et al. 2006), in human circulating melatonin
(Cornélissen et al. 2008), in human SBP and DBP and in a 15-year series of mostly daily excretions of urinary 17-ketosteroids, critical for survival and reproduction (Halberg et al. 2008b).

\section{Maps of congruent periods}

It is desirable to test long physiological time series and, when possible, aligned physical environmental series for congruence only when the lower limits of the CIs of the amplitudes of cycles considered do not overlap zero, i.e., the zero-amplitude assumptions have been tested and rejected (Halberg 1980, Cornélissen and Halberg 2005, Refinetti et al. 2007). The CIs of the periods are then said to be congruent when their CIs overlie or overlap each other, Figs 6A-E. By a method such as the extended linear-nonlinear cosinor (Halberg 1980, Cornélissen and Halberg 2005, Refinetti et al. 2007), as predicted (Halberg et al. 1991, 2000), we find a set of congruences of reciprocal periods in and around us, but not necessarily with congruent phases, Fig. $6 \mathrm{~F}$. At the same periods, we sometimes find clearly divergent phases, changing gradually up to a point or suddenly, involving jumps, Fig. 6F (see also Fig. 5C).

In WRB, morning BP measurements show intra-individual congruence for his SBP and DBP as well as for body weight in the tridecadal range. Each variable has a transtridecadal period with a CI overlapping the range extending from 30 to 40 years, Fig. 7A (Halberg et al. 2009a). It must be emphasized that measurements at a fixed time of day cannot be generalized and that different tridecadal results have been obtained from time series based on various fixed times of day from observations on the same person (Halberg et al. 2008d). Intra-individual transtridecadal congruence can come about when the point estimates of periods are close, as is the case for SBP and DBP of WRB, or because the CIs of the periods are great, as is the case WRB's body weight.

The SBP of FH exhibits an about 11-year and his DBP an about 15 -year component. FH's HR has an about 30-year cycle, providing an apparent good fit to the daily means, Fig. 7B (Halberg et al. 2009c). The CIs of these three periods do not overlap each other. Thus, in the sense of overall parameter estimation on the entire time series, for the same two variables (SBP and DBP), there can be intra-individual decadal/multidecadal acongruence (in $\mathrm{FH}$ ) or transtridecadal congruence (for WRB). Congruence can also be tested for a given biospheric cycle with each solar-ionospheric-terrestrial component, all summarized with estimates of the uncertainty also of the period, i.e., with inferential statistical validation and replication. Thus, for biological variables, we can 


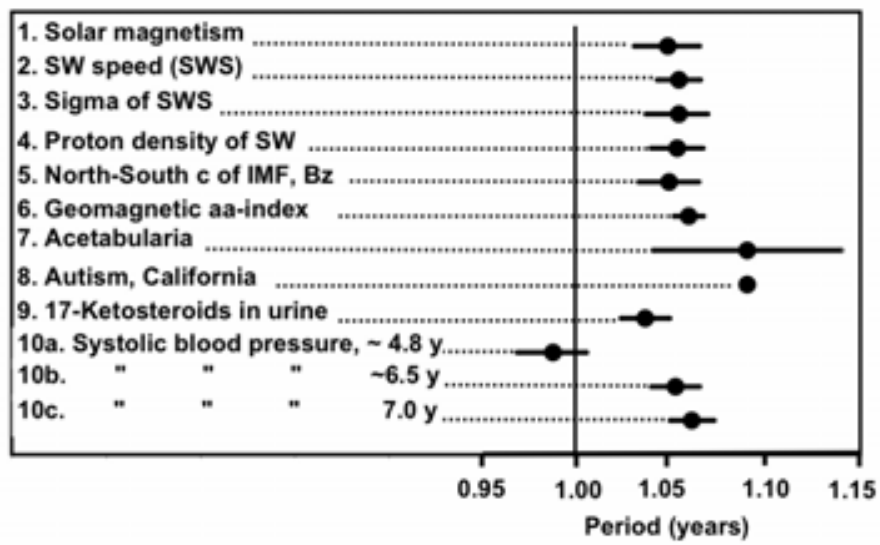

Fig. 6A. Map of an environmental-biospheric near-transyear (first 9 rows). As a man (GSK) ages and/or his measurement series gets to be longer, a near-transyear emerges (rows 10a-c).

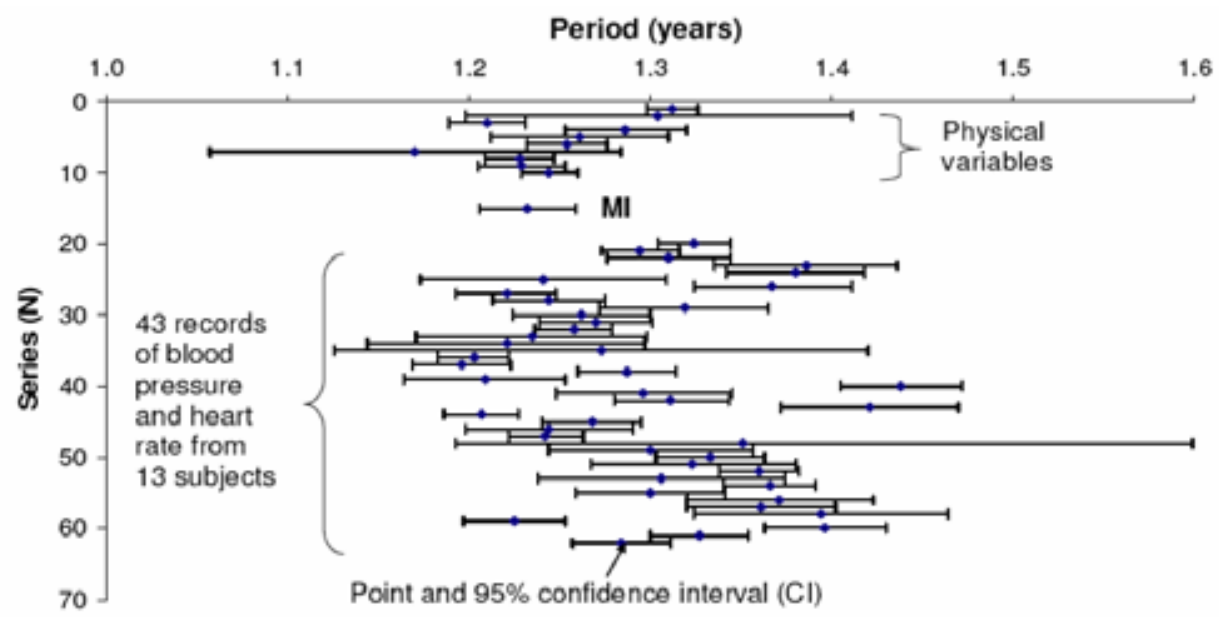

Fig. 6B. Map of environmental-biospheric far-transyears.

seek and find counterparts in the cosmos that must also be examined with their uncertainties, as examples of transdisciplinary congruence, as shown for FH in Figs 7C-E. Vice versa, we can look for markers of environmental cycles in the biosphere. Reciprocity of periods does not mean any arithmetic relation. It is no more than the correspondence in length of periods in us and around us, gauged by their CIs. There is thus intra-individual congruence (Fig. 7A) or acongruence (Fig. 7B). Some inter-individual (intra-disciplinary) transtridecadal congruence characterizes several circulatory variables of WRB, FH and RBS, three men with long records, as shown in Fig. 7F for HR of RBS as well as of FH and for SBP (as well as DBP and body weight) of WRB, findings showing the need to refrain from generalizations at this stage of lack of knowledge. Infradian multidecadal congruence, and accordingly synchronization are not invariably found. Intra-individual decadal-multidecadal acongruence characterizes FH (Fig. 7B), since his SBP, DBP and HR have no overlapping CIs of their periods. We now refer to acongruence that can characterize different variables of the same organism, probably as a result of a selective environmental congruence, as remains to be determined for FH, whose SBP perhaps mimics the long-term course of the Horrebow-Schwabe cycle in Wolf's relative sunspot numbers (Cornélissen et al. 2009), while his DBP, with a cycle of about 15 years, perhaps mimics Makarov and Sivaraman's (1989) global cycle in solar activity and FH's HR reveals an about 30-year cycle of Brückner, Egeson and 


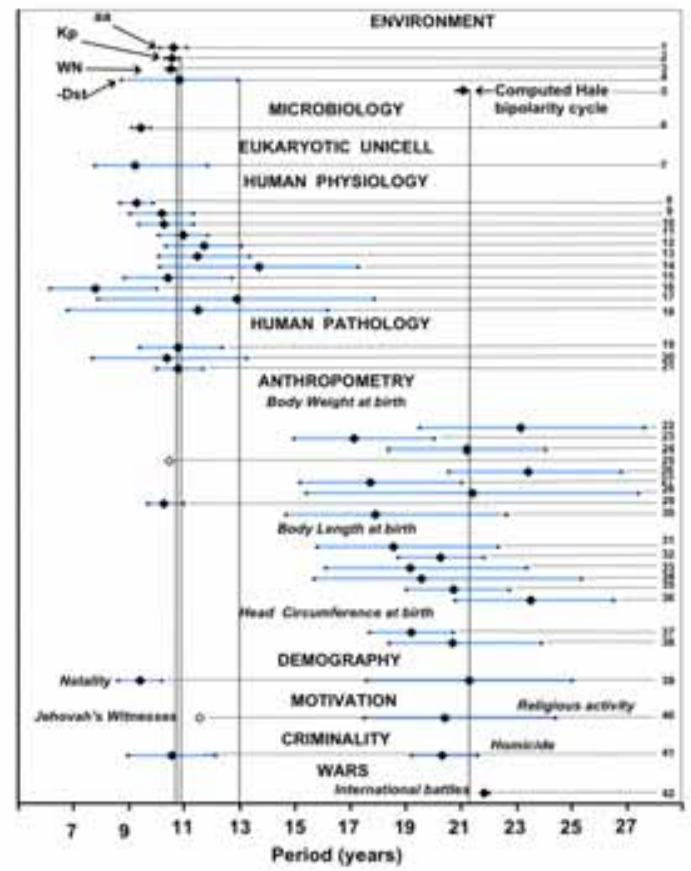

Fig. 6C. Map of environmental-biospheric decadal-didecadal cycles. See Halberg et al. (2002) for key to variables.
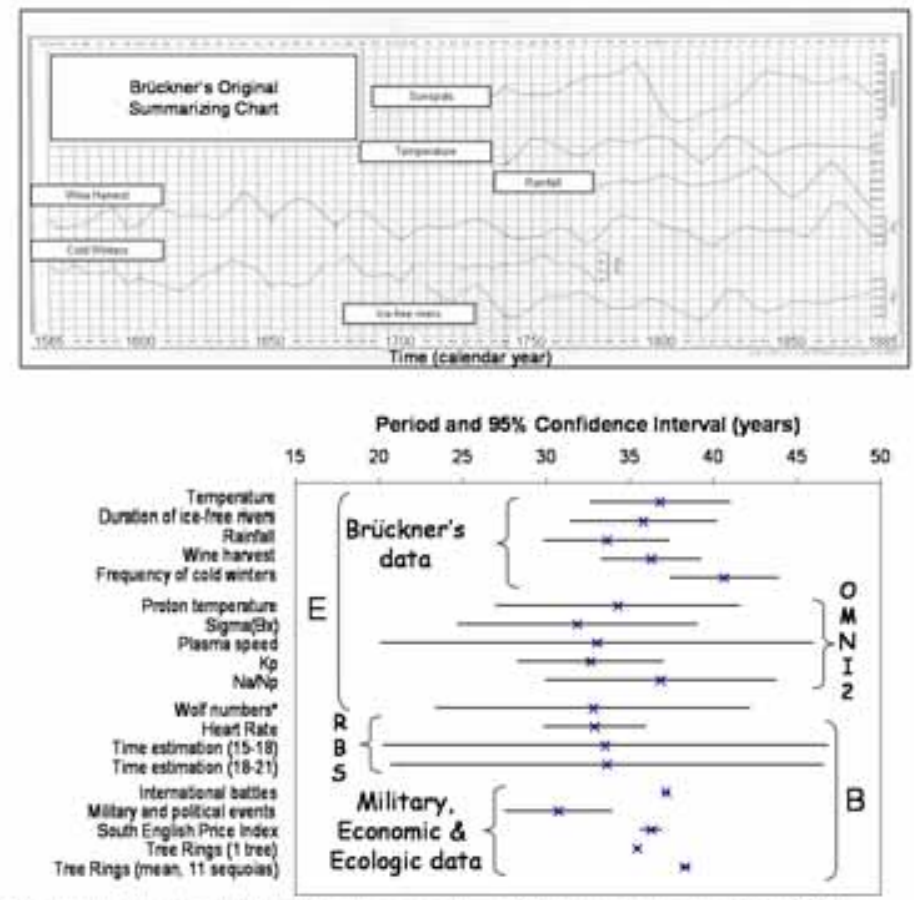

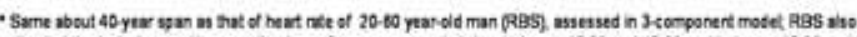

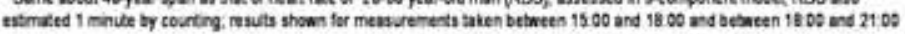
E: Environment; B: Biosphere

Fig. 6D. Display of original climate data (top) and map of environmental-biospheric transtridecadal Brückner-Egeson-Lockyer (BEL) cycles (bottom). The BEL cycle in Brückner's data (first 5 point-and-interval period estimates) is also detected by spectral analysis in military, economic and ecological data and in physiological data from RBS (see also Fig.s 7I and 7J) and from two other men (see Fig. 7F), as well as in many other population phenomena, the mechanisms of which become available to study on individuals for investigators who try to plan beyond their lifespans. 


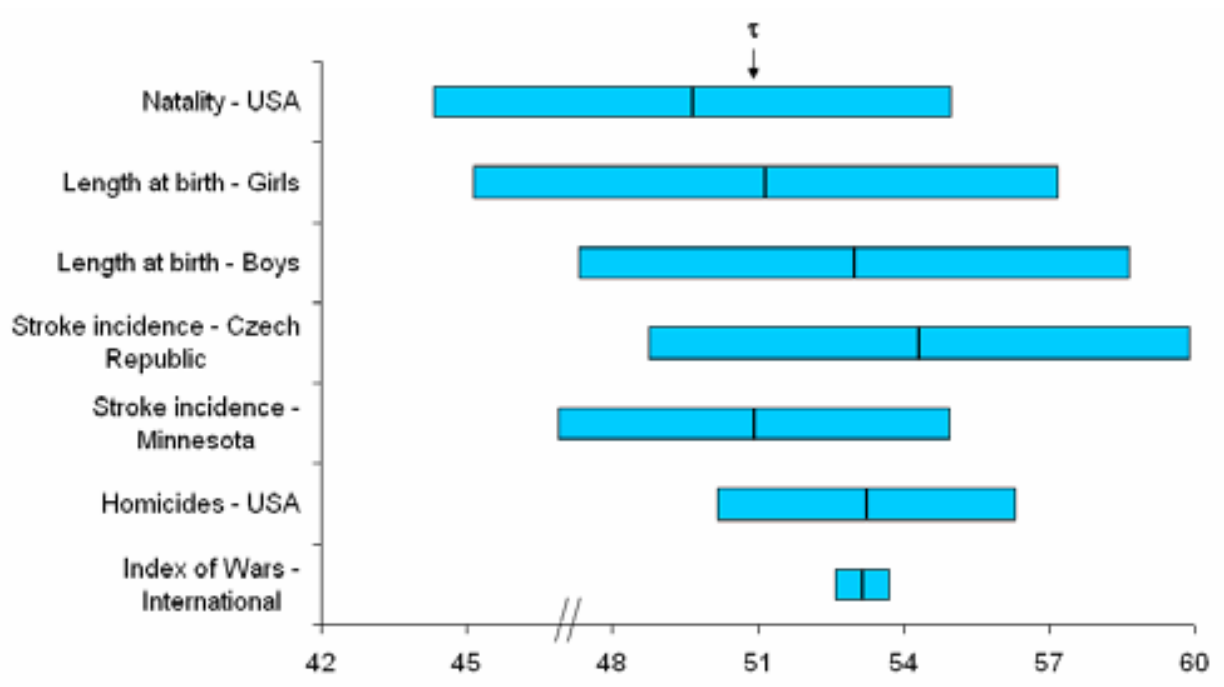

Nonlinear Period Estimate ( $\tau$ ) and 95\% Confidence Interval (years)

Fig. 6E. Map of environmental-biospheric quindecadal cycle (Halberg et al. 2002).

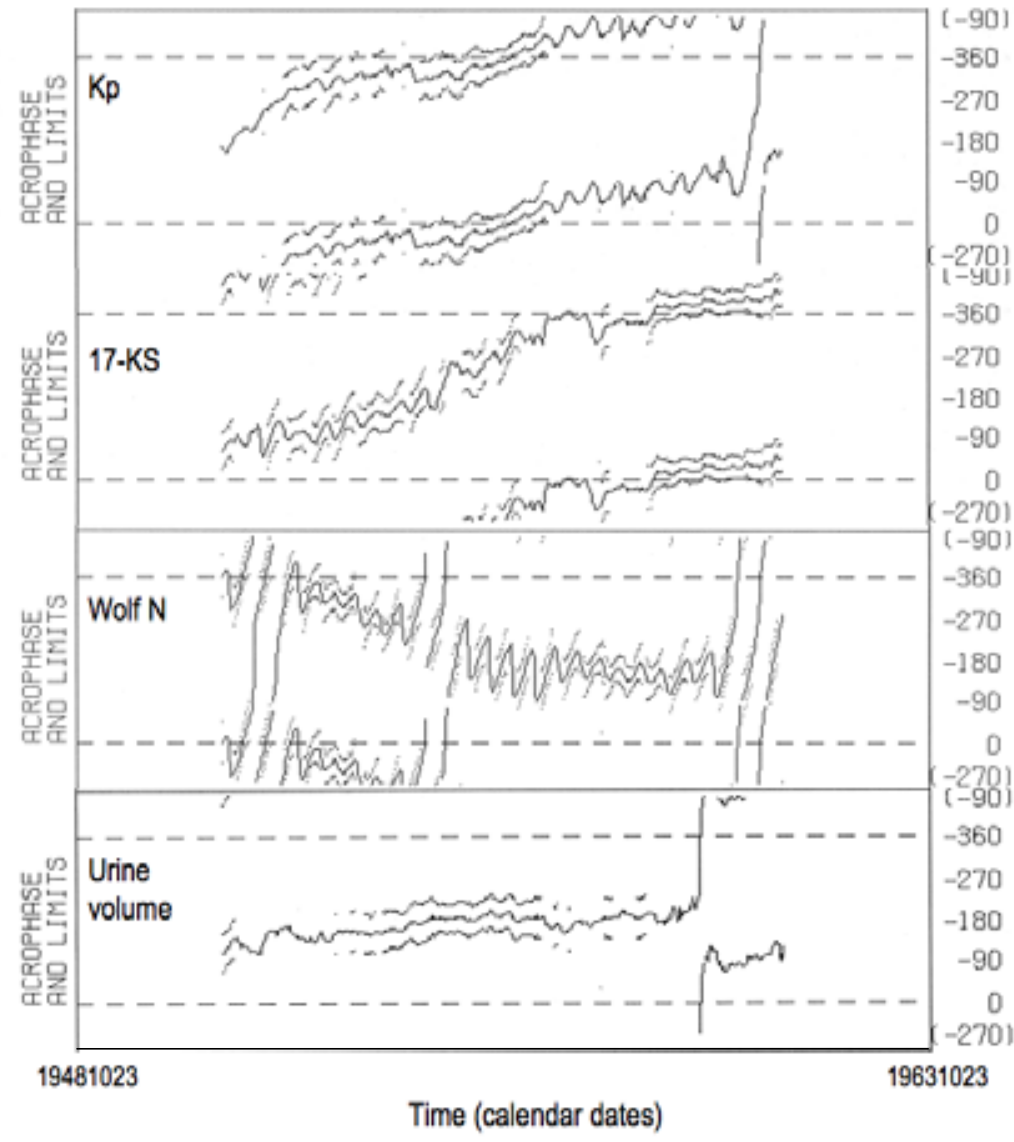

Fig. 6F. Different time course of acrophases from the fit of a 154-day cosine curve among environmental-biospheric cycles that are congruent in period (latter not shown). Note similar behavior of acrophases of the geomagnetic planetary index Kp and the urinary excretion of breakdown products of steroidal hormones that, however, differ from the behavior of acrophases of the same 154-day cosine in Wolf sunspot numbers and in the volume of the urine in which the steroids were determined. Interval = 5 years; increment $=1$ week. 


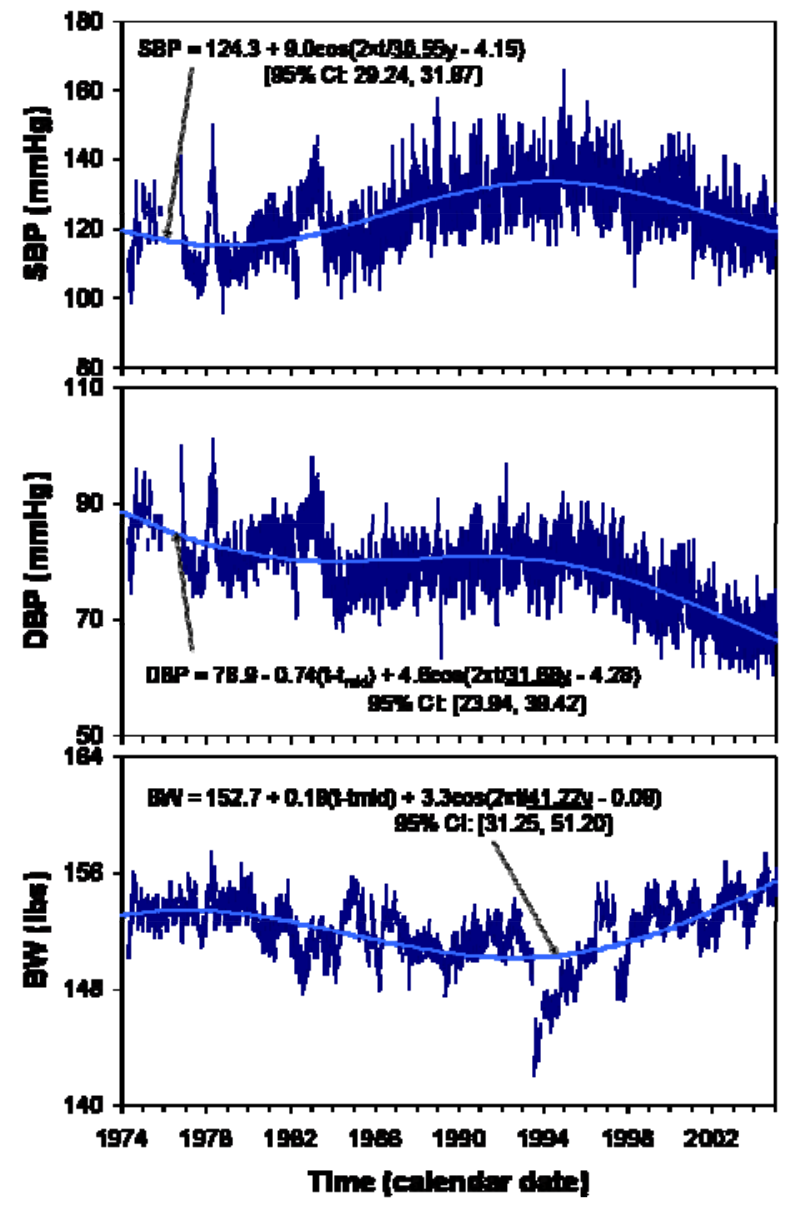

Fig. 7A. Intra-individual transtridecadal congruence of the periods of SBP, DBP and body weight in morning measurements continued for about 30 years by WRB. Results on DBP and body weight obtained with the concomitant fit of a linear trend. Note intra-individual differences in acrophase among congruent periods in fitted mathematical models. This multivariable intra-individual transtridecadal congruence, involving body weight as a gauge of metabolism beyond the circulation, is also intra-disciplinary, but cannot be generalized to all humans (see Fig. 7B). Nonetheless, transtridecadals (BELs) found in other biospheric and terrestrial and extraterrestrial climatic variables (see Fig. 6D) render such congruences transdisciplinary as well.

Lockyer, called BEL. Cycles longer than decadal and shorter than didecadal are also found by S. R. Prabhakaran Nayar with wavelet analysis in solar wind proton density and in SWS and based on linear-nonlinear rhythmometry by ourselves. Linearly, there is congruence of speed and density for about 17-year components, yet acongruence for transtridecadals, with the latter lost with the particular modeling used for FH (Fig. 7B and 7F). Congruence depends on the period, the time span, the individual(s) or populations, the variable(s) and spectral regions considered, Tables 1 and 2.

Validation of cyclicity for variables self-measured by RBS reveals that there is didecadal congruence of SBP and DBP (Figs $7 \mathrm{G}$ and $7 \mathrm{H}$ ), while there is acongruence of these two variables with RBS' HR,
Fig. 7I (SBP was acongruent with both DBP and HR for FH, Fig. 7B). In WRB, there may be tridecadal congruence of three different variables (Fig. 7A) during the same time spans that yielded acongruence for some of the same variables of FH (Fig. 7B), and intra-individual acongruence for RBS (Fig. 7J) as a basis for a selective environmental congruence (Fig. $7 \mathrm{~K})$. RBS also showed selective congruence in the para-annual and para-semiannual spectral regions, Fig. 7L and Tables 1 and 2. From 40 years of self-measurements of SBP, DBP and HR by RBS, Fig. $7 \mathrm{~K}$ reveals global relations (based on analyses of the entire 40-year series) with the about 10.5-year cycle in Zürich (Wolf) sunspot numbers (WN), Hale’s about 22-year bipolarity sunspot cycle (BSC, constituted by changing the sign of $\mathrm{WN}$ at 

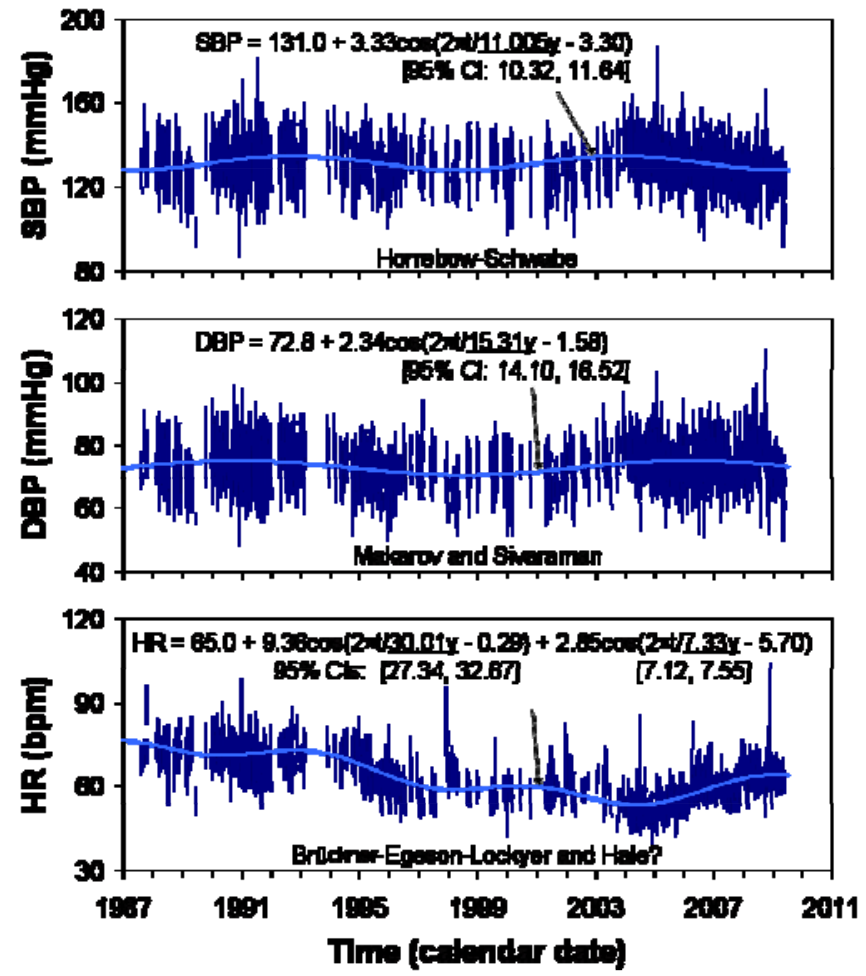

Fig. 7B. Illustration of intra-individual acongruence in the decadal-multidecadal spectral region of FH.

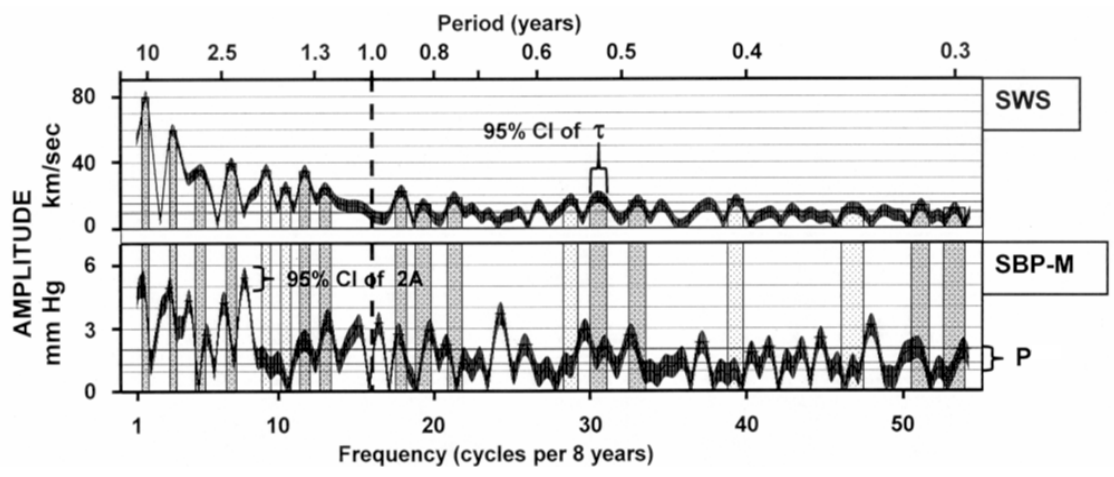

Fig. 7C. Solar wind speed's congruences with SBP of FH.

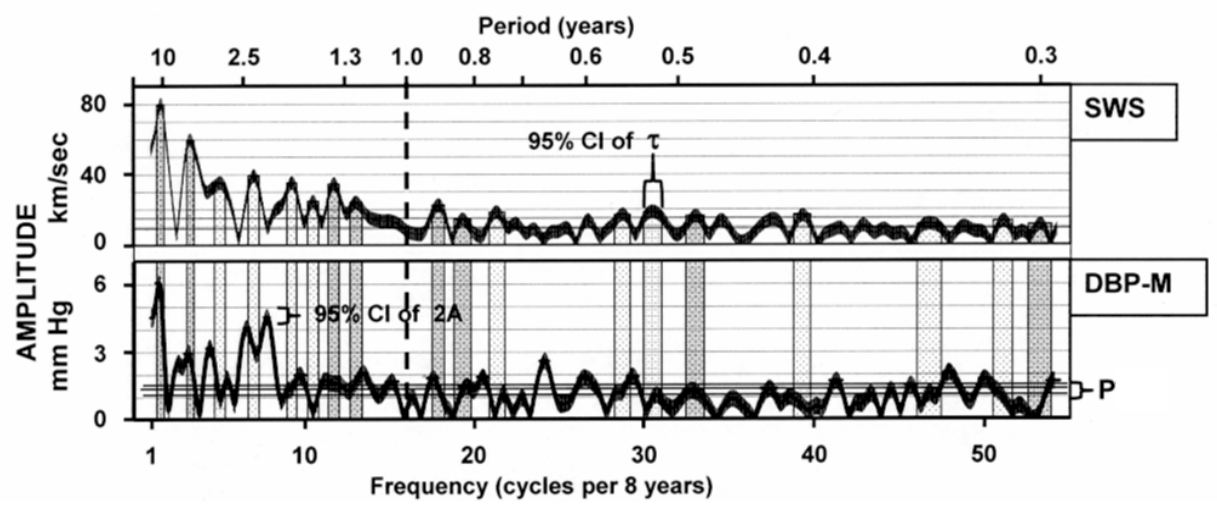

Fig. 7D. Solar wind speed's congruences with DBP of FH. 




Fig. 7E. Solar wind speed's congruences with HR of FH.
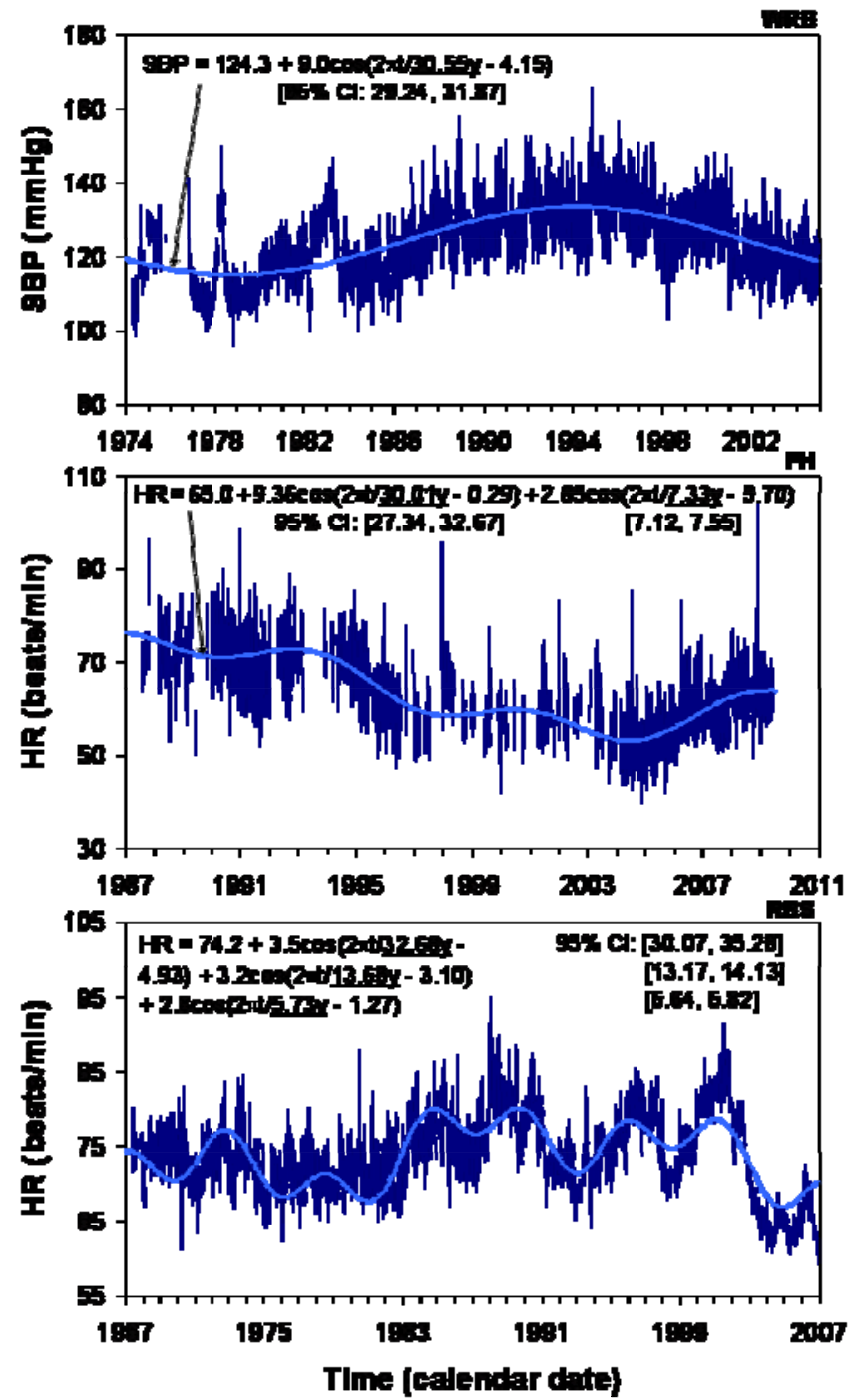

Fig. 7F. Inter-individual transtridecadal congruence of different variables in the circulation of blood in three men, RBS vs. WRB (see Fig. 7A) and FH (see Fig. 7B). 


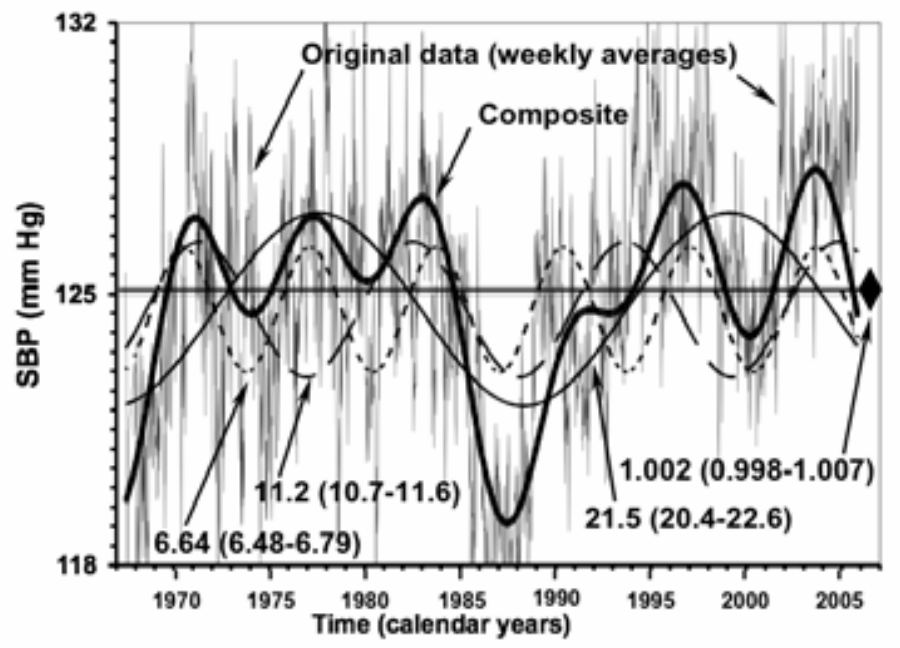

Fig. 7G. For RBS's SBP, a didecadal cycle with a period of about 21.5 years, apparent in the original data, covers, with its CI, the period estimate of his DBP, shown in Fig. $7 \mathrm{H}$.

consecutive circadecennian WN minima; cf. Prestes et al. 2006) ${ }^{4}$, and the geomagnetic antipodal index aa (Gaa). The signature of a transtridecadal BrücknerEgeson-Lockyer (BEL) cycle, here gauged by WN, found in many climate and biosphere variables, is congruent with RBS' HR (left), as shown by the overlying CIs of the about 33-year (BEL) period in WN and in RBS' HR. The same person's DBP is congruent (has overlapping CIs of the period of a spectral component) with Hale's bipolarity cycle (second shaded pair of CIs of periods in Fig. 7K).

\section{DISCUSSION}

Many long time series are needed to systematically examine any intra-disciplinary congruence or acongruence at each period, globally and time-varyingly in different variables of the same discipline, such as physiology, pathology or sociology. In the only three cases available to us covering a sufficiently long span to detect tridecadals, this BEL cycle was found in one (RBS and $\mathrm{FH}$ ) or three variables (WRB). Intra- and inter-individual congruences and other intra-disciplinary congruences are best explored prior to examining any congruence of periods in two or more disciplines for interdisciplinary congruences between two disciplines and further for the transdisciplinary ones among many more fields, Fig. 7K. For the BEL cycle, transdisciplinarity has been extensively documented (Halberg et al. 2009d).

Periods in the biosphere congruent with overlapping if not overlying uncertainty with helio- or geomagnetics are found in several different spectral regions of a given variable or system of variables. Transdisciplinary congruences of periods are also found in the usually 24-hour synchronized circadian and about 7-day (circaseptan) systems, in about 5-month (cis-half-year) (Cornélissen et al. 2008) and 6-month (Cornélissen et al. 2003) systems, and are documented in the transyear (Halberg et al. 2003b, Cornélissen et al. 2004, 2007a, Kováč and Mikulecký 2005, 2006, Mikulecký and Florida 2005, Mikulecký 2006) and circasemimillennial (Halberg et al. 2004, Mikulecký 2007) spectral regions, to cite but a few examples.

Overlapping CIs of periods in and around us are selective insofar first as in the same person (RBS) the same biotic variable can be congruent with a solar variable at one frequency and with a terrestrial variable at another. Major environmental cycles such as those of about 30 and about 20 years can have different biotic counterparts in BP versus HR, as reciprocal periods, all facts of the selective assortment characterizing our cosmic inheritance of cycles, Fig. $7 \mathrm{~K}$. In other regions of the spectrum, such as the

\footnotetext{
4) Prestes et al. (2006) write that "The 22-year Hale cycle was not detected either in Rz or aa spectrum in the period 1868-2001, but it was seen in Rz data for 1700-2000 annual averages". (Rz is another notation for Wolf numbers.)
} 


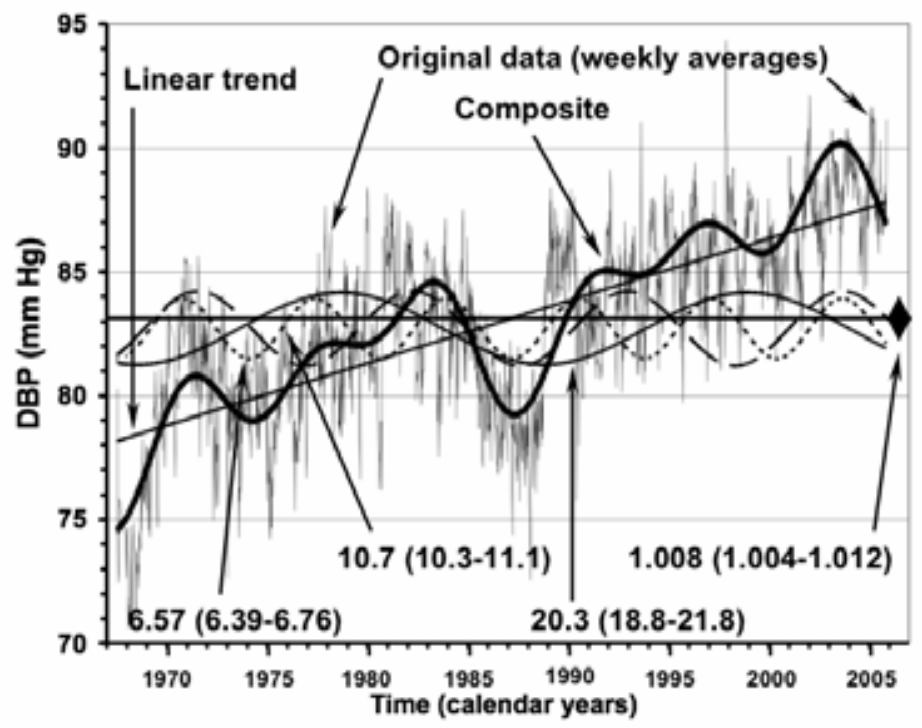

Fig. 7H. For RBS's DBP, a didecadal cycle with a period of about 20.3 years, complicated by a linear trend, covers, with its CI, the period estimate of his SBP, shown in Fig. 7G.

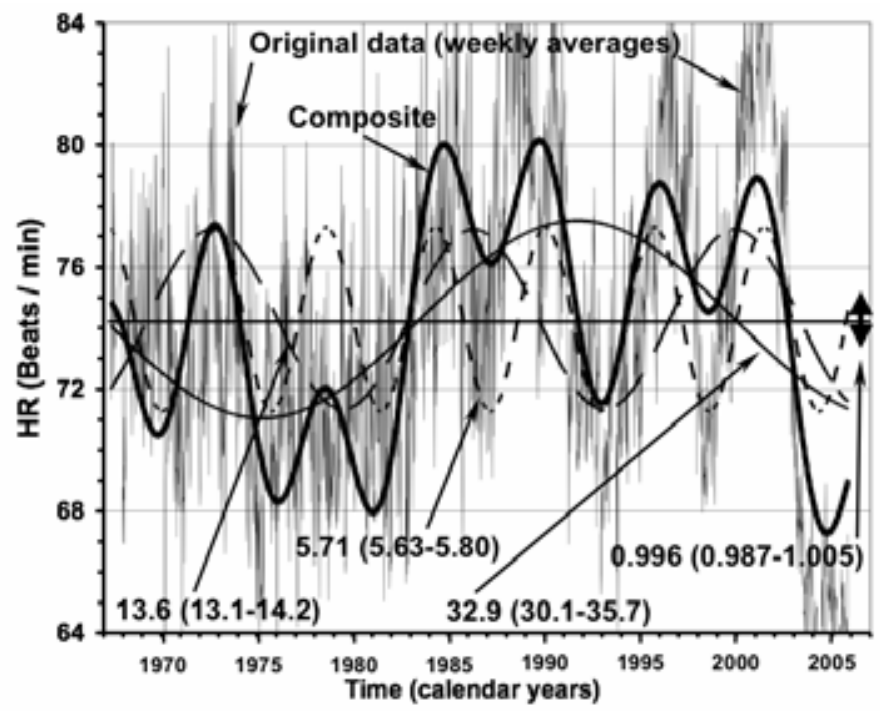

Fig. 7I. For RBS's HR, there is no trace of a didecadal cycle seen in Fig. 7G and 6H for his SBP and DBP.

para-annual and para-semiannual regions, in the range of periods between 0.3 and 2.0 years, there is biotic congruence with one or both, helio- and geomagnetics or with neither. As seen in Fig. 7K, in Tables 1 and 2 and in Figs 6A, 6B and 7C-E, a congruence of periods is found in the para-annual and para-semiannual regions of the spectrum, very often with SWS or with geomagnetism, the latter gauged by the antipodal index aa, for a human mental function (the estimation of 1 minute) carried out around-the-clock on most days for well over 3.5 decades. Overall, there is the anticipated congruence between periods in SWS and aa in $24 \%$ of the cases, insofar as 5 of the 21 spectral peaks in SW have a counterpart in aa, once we restrict focus upon the para-annual and para-semiannual spectral regions. There is actually congruence in $29 \%$ insofar as 5 of the 17 SWS peaks have aa counterparts for a mental 


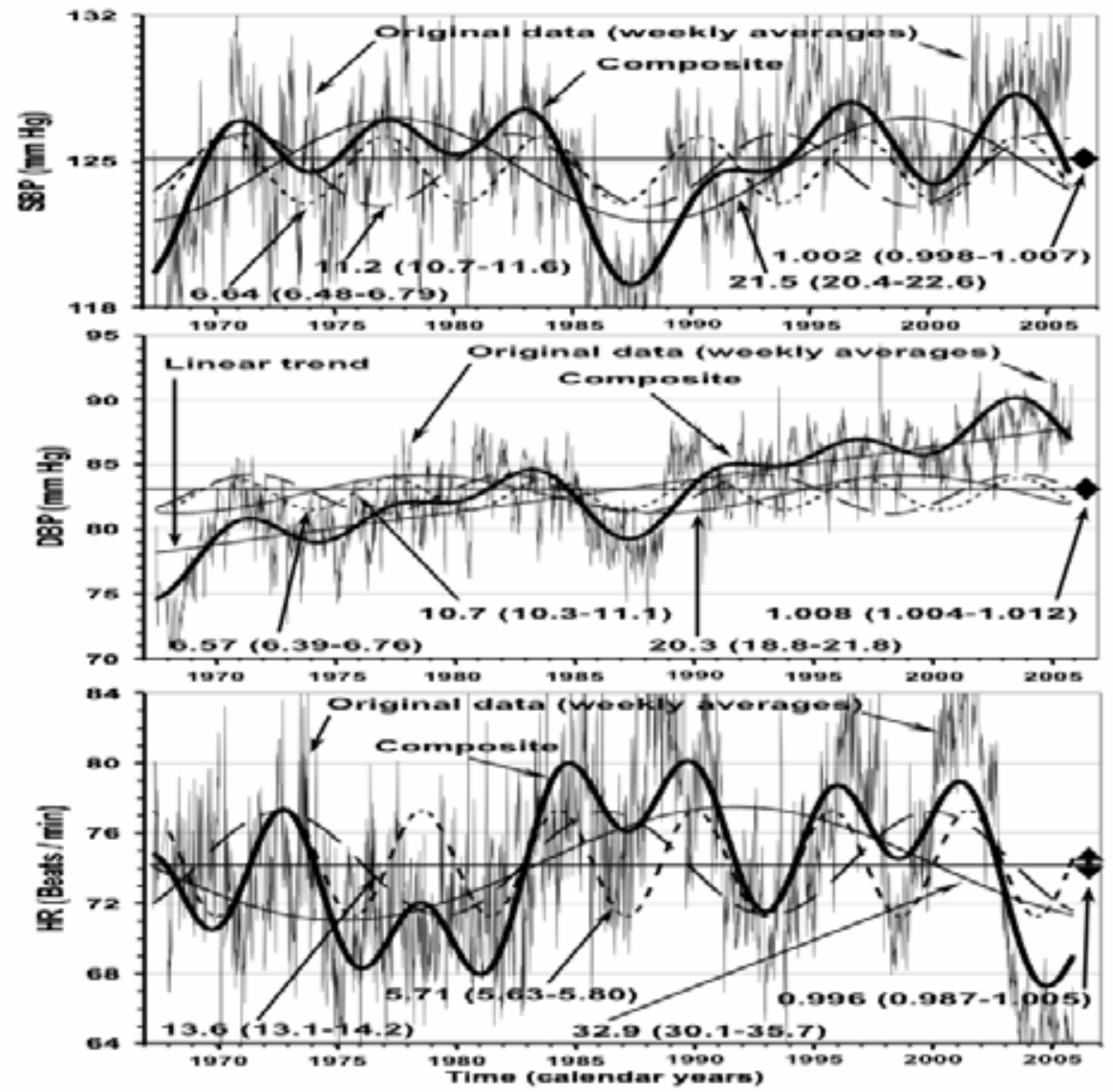

Fig. 7J. Intra-individual acongruence, a requirement for selective biospheric-environmental congruence (see Fig. 7K).

function, the estimation of 1 minute, in this region, as can be seen from Table 1 and Fig. 7L. Table 2 shows further congruences of psycho-physiologic variables with SWS and/or aa.

Rules of cycles' inheritance from the cosmos Endogenicity was clear for some ultradian rhythms, as in the case of cardiac cells beating in vitro (Han et al. 1991) or of the heart in toto doing so. The built-in nature of circadians was documented by statistically significant intra-class correlation coefficients of the MESOR, amplitude and acrophase of HR of monozygotic twins reared apart, many of whom met for the first time in Minnesota (Hanson et al. 1984), Figs 8A-C. Our inferential statistical documentation of periods longer than 28 hours, up to over 30 years by both global and time-varying analyses allows a summary herein of the rules of inheritance of infradian biospheric cycles that mimic those of the cosmos.
Rule 1, indispensable but not sufficient, is congruence in period, not necessarily in phase, documented by overlapping CIs of infradian periods, in various regions of the spectra from multiples and submultiples of 7 days (multiseptans) up to periods longer than 30 years (transtridecadals). In the case of decadals, notably of transtridecadals, a documentation of the rule of a minimum of three cycles needed to document a rhythm can be sought (and was found) transversely across three individuals, rather than longitudinally in the same individual, as seems reasonable, even for centenarians. Likely changes with age in the cycles' behavior found for transyears remain to be documented for decadals and multidecadals.

Rule 2 is a selective assortment of the biospheric-cosmic pairing differing among individuals, e.g., of $\mathrm{HR}$ with a transtridecadal environmental cycle and of BP with a didecadal cycle in RBS or of SBP with a Horrebow-Schwabe decadal cycle, DBP with putatively a global cycle, and HR 


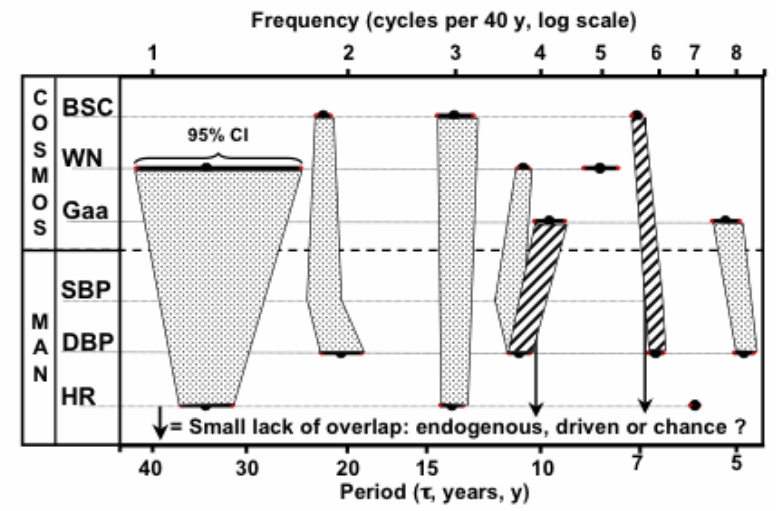

Fig. 7K. Selective environmental congruence seen for RBS.

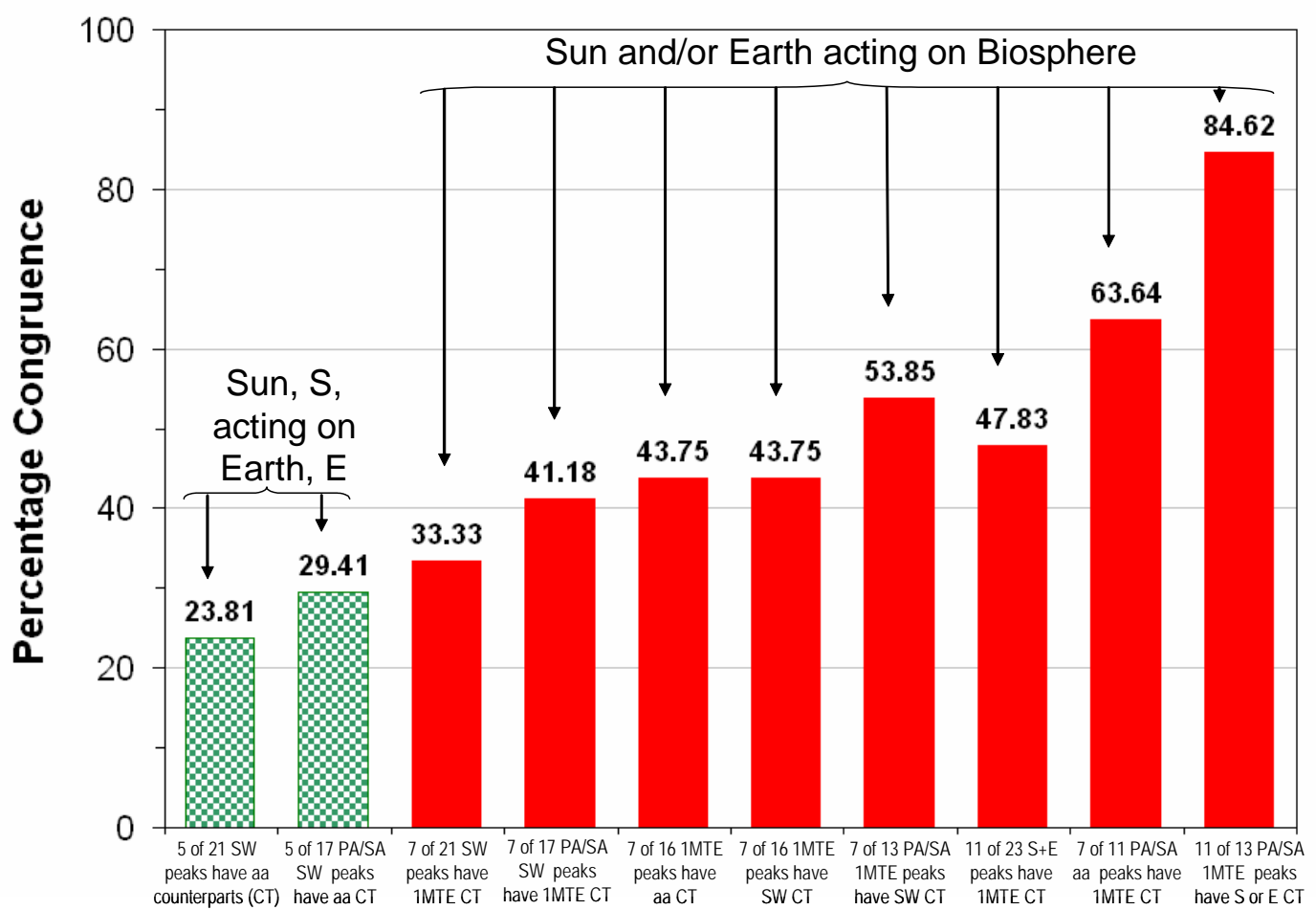

Fig. 7L. Congruence between the magnetism of earth and sun (columns 1-2) vs. congruence of helio- or geomagnetics with a human mental function (columns 3-10). Note numerically higher percentage of congruence between either helio- or geomagnetics and the biosphere as compared to congruence between solar and terrestrial magnetism. PA/SA: paraannual/semi-annual spectral region.

with a BEL likely in FH. By reference to these first two rules, we are influenced by Mendel's laws of segregation and independent assortment of what became genes.

Rule 3, a "consistent subtractive and/or additive behavior", was examined when the opportunity arose by subtraction (up to removal) from and/or addition to the transdisciplinary spectrum of an environmental component to determine whether it entailed corresponding changes (damping or amplification, Fig. 8D, or pull of phase, Fig. 8E) in the biosphere.

Rule 4 is the genetic coding of the biospheric cycle, revealed at the molecular level for circadians and perhaps at the atomic level (Ulmer et al. 1995) for some circaseptans and for other infradians as yet only by rule 3 , the damping, yet persistence, following the removal of a corresponding environmental component. This rule validates the long-term 


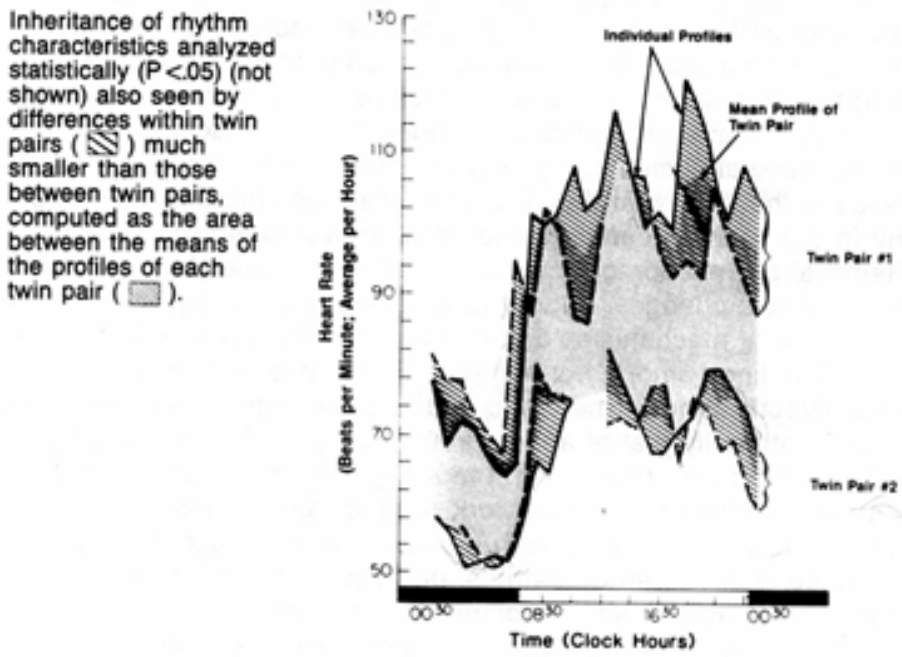

Fig. 8A. Circadians were documented as inherited by intra-class correlation coefficients $\left(\mathrm{r}_{\mathrm{I}}\right)$ (all statistically significant) of the MESOR, amplitude and acrophase of HR (monitored for 24 hours beat-to-beat) of monozygotic twins reared apart, many of whom met for the first time in Minnesota. The computation of $r_{I}$ demonstrates heritability separately for each characteristic. Heritability was documented earlier indirectly by studies of a free-running rhythm during human isolation for several months in a cave. This Fig. is oversimplified, conveying the concept of inter- and intra-twin-pair variability with data from only two pairs of twins. In order to obtain a valid estimation of the inheritance of circadian rhythm characteristics of HR, data from a larger number of twin pairs are needed. A summary of results from 21 twin pairs serves this purpose. The result of a statistical computation ( of $\mathrm{r}_{\mathrm{I}}$ ) indeed documents a genetic basis for three circadian rhythm characteristics of human HR.

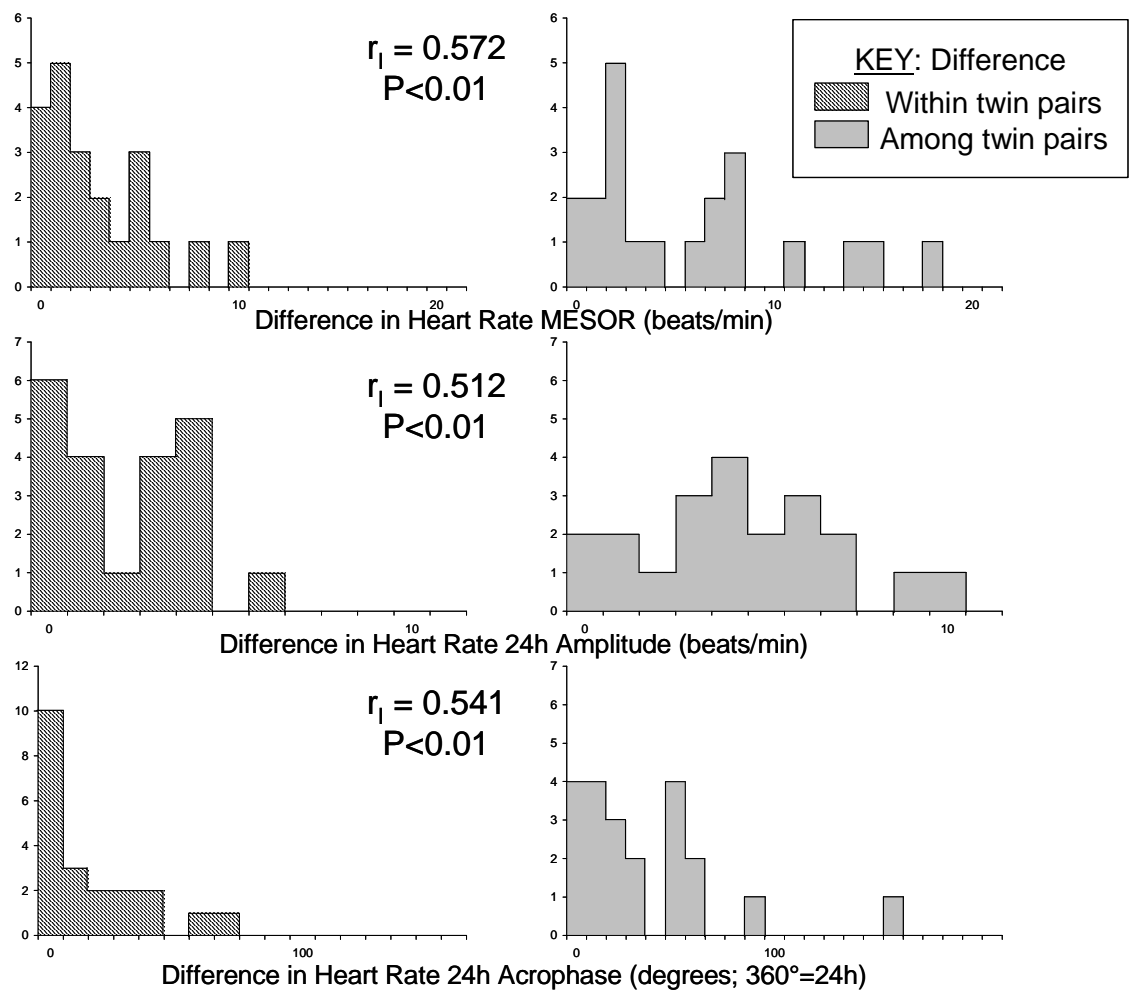

Fig. 8B. The results from monozygotic twin pairs reared apart. At the time of study, they had a mean age of 32.8 years. Their mean age of reunion was 16.1 years, and they were on the average 2.9 months old at separation. Half the sets were studied within 6 months of finding each other. Each twin of a pair was monitored during the same week, although not necessarily on the same day. 


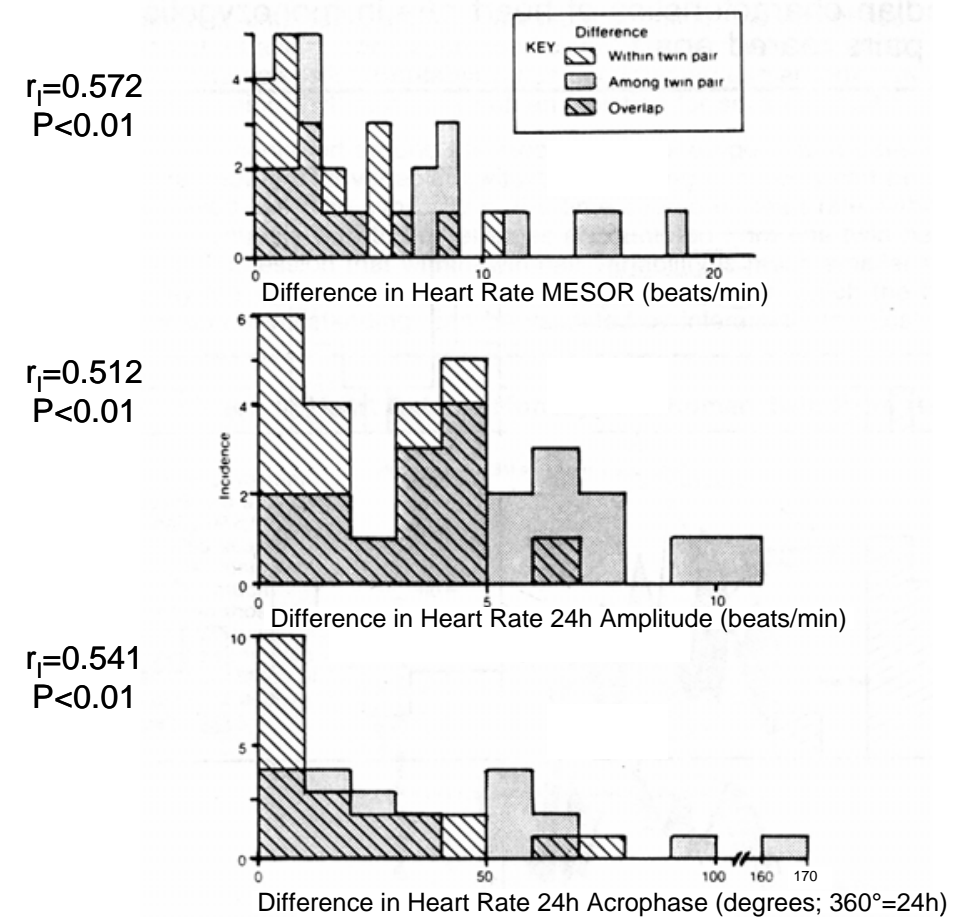

Fig. 8C. The intra-class correlation coefficient (rI) is used herein to test the heritability of circadian rhythm characteristics of human HR. Heritability is demonstrated for all three parameters, MESOR (M), amplitude (A) and acrophase ( $\Phi)$ (all statistically significant).

A
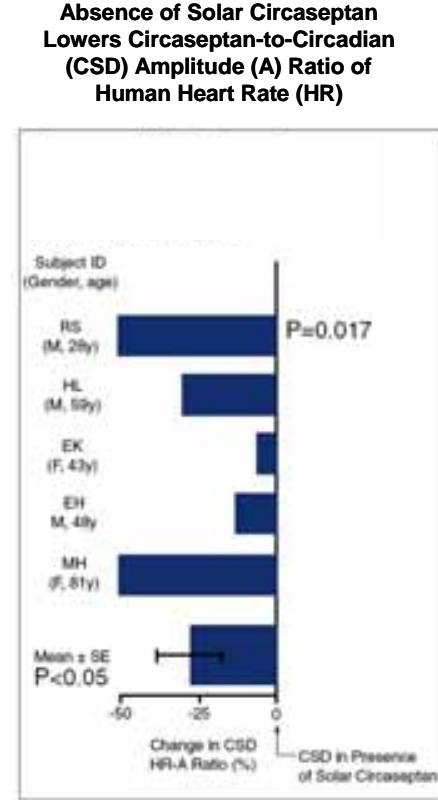

S and $A$

\section{B}

After Loss (at E) of Entire 1.3-year Band in Solar Wind Speed (SWS), this Band Persists in Part (at E') in Human Systolic Blood Pressure (SBP)

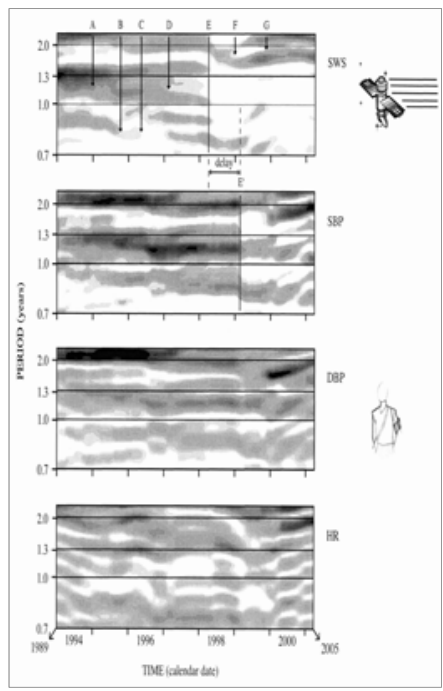

S

\section{C}

A Congruent 16.27-month (1.36-year) Component $(\boldsymbol{L})$ in Terrorism (MIPT) Lags that in Solar Wind Speed (SWS) and Geomagnetism (aa)

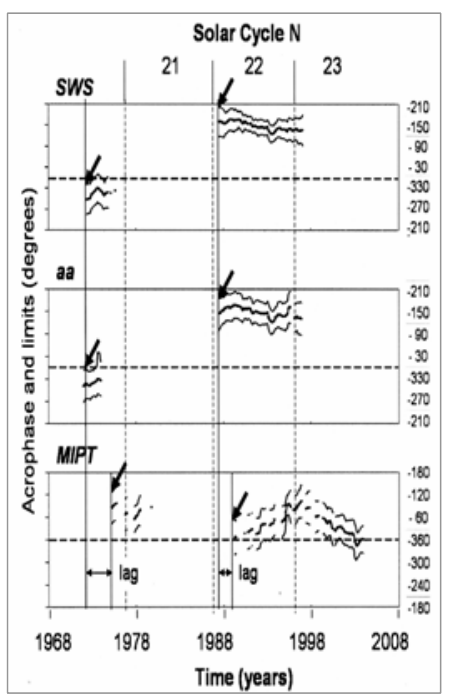

A and $S$

\section{S: Subtraction (or removal); A: Addition (or replacement)}

Fig. 8D. A lesser prominence of an about 7-day spectral component in the HR of 5 men is found when the solar wind loses its counterpart (left). Implied, but not shown, is the persistence in the biosphere of an about 7-day component that can be driven (amplified) by a reciprocal component in solar activity. There is partial resonance of the about 1.3-year component in the SBP 
of FH with SWS (middle). Non-stationary intermittent frequencies are seen to characterize SWS (top row). These, like those in SBP, are called Aeolian (derived, as a personification of the solar wind, as Aeolus, Greek ruler of winds), the use of the term implying, however, that interval as well as point estimates of the periods are provided, at least globally and, whenever desirable, time-varyingly in chronomic serial sections, complementing gliding windows. SWS, like SBP, changes in frequency, smoothly $[\mathrm{A}]$ or abruptly $[\mathrm{B}, \mathrm{C}, \mathrm{D}]$, bifurcating $[\mathrm{D}, \mathrm{F}]$ and rejoining $[\mathrm{G}]$, and varies in amplitude $[\mathrm{B}]$, up to disappearing $[\mathrm{C}, \mathrm{E}]$ and reappearing. An abrupt change in SWS is followed in SBP with a lag by changes such as the narrowing (disappearance of part) of a broad band and the damping of the remaining part of the about 1.3-year [1.22- to 1.38-year] far-transyear component in SBP, previously congruent with a counterpart in SWS and by the disappearance of part of a cis-year. This finding suggests that some of FH's cis- and transyear components were driven by the solar wind. Note also that part of a far-transyear band disappeared with a lag of about a far-transyear following the disappearance (subtraction) of the same components from the SWS spectrum. The lag in the disappearance from SBP of a cis-year component of about 0.66 year is the same (not shorter) as that for the transyear, suggesting the possibility that it represents a harmonic of a non-sinusoidal far-transyear. Specifically, after the broad band disappears in the SWS (at E), parts of the same broad band in SBP also disappear, with a lag (delay) at E', while other parts, albeit damped, persist. This persistence of a narrower damped band in the spectral domain suggests prior driving of a component with partial endogenicity, i.e., an evolutionary acquisition of biotic transyear oscillations that may reflect solar dynamics for the past billions of years. Post hoc ergo propter hoc reasoning can never be ruled out. $\mathrm{N}=2,418$ daily averages of BP and HR data; total $\mathrm{N}=55,000$, from automatic around-the-clock monitoring for nearly 16 years, mostly at 30 -min intervals, with interruptions. Gliding spectra computed with an interval of 8 years have a resolution low in time but high in frequency. The increment is 1 month and trial periods range from 2.5 to 0.4 year(s), with a harmonic increment of 0.05 . Darker shading corresponds to larger amplitudes. Congruence in both time and frequency is found for the about 1.3-year component of terrorism with respect to both SWS and aa (right). Peaks of best fitting cosine curves ( $\Phi s)$ and parts of chronomic serial sections show a statistically significant about 1.3-year far-transyear in both SWS (top) and in the antipodal geomagnetic index aa (middle), followed on each of two occasions with a lag by a statistically significant about 1.3 -year component in terrorism which by far outlasts the apparently triggering putative heliogeomagnetic drivers ( $\Phi$ s are plotted only when the 1.3-year amplitude differed from zero with statistical significance, as shown by dots bracketing the point estimates of the acrophase, indicative of the CIs of $\Phi$ s in each interval). Noteworthy further, but not shown, is that a transyear replaces the calendar year in a 39-year series of terrorist acts, suggesting the importance of transyears in military-political affairs, with the same finding of a transyear, as a replacement of the seasons, in the popularity of a U.S. president. These and/or other non-photic signatures pervade human affairs, including military and political activity, economics and health. Transyear and cis-half-year patterns are pertinent to sudden cardiac death, a condition wherein magnetic storms may be protective rather than noxious.

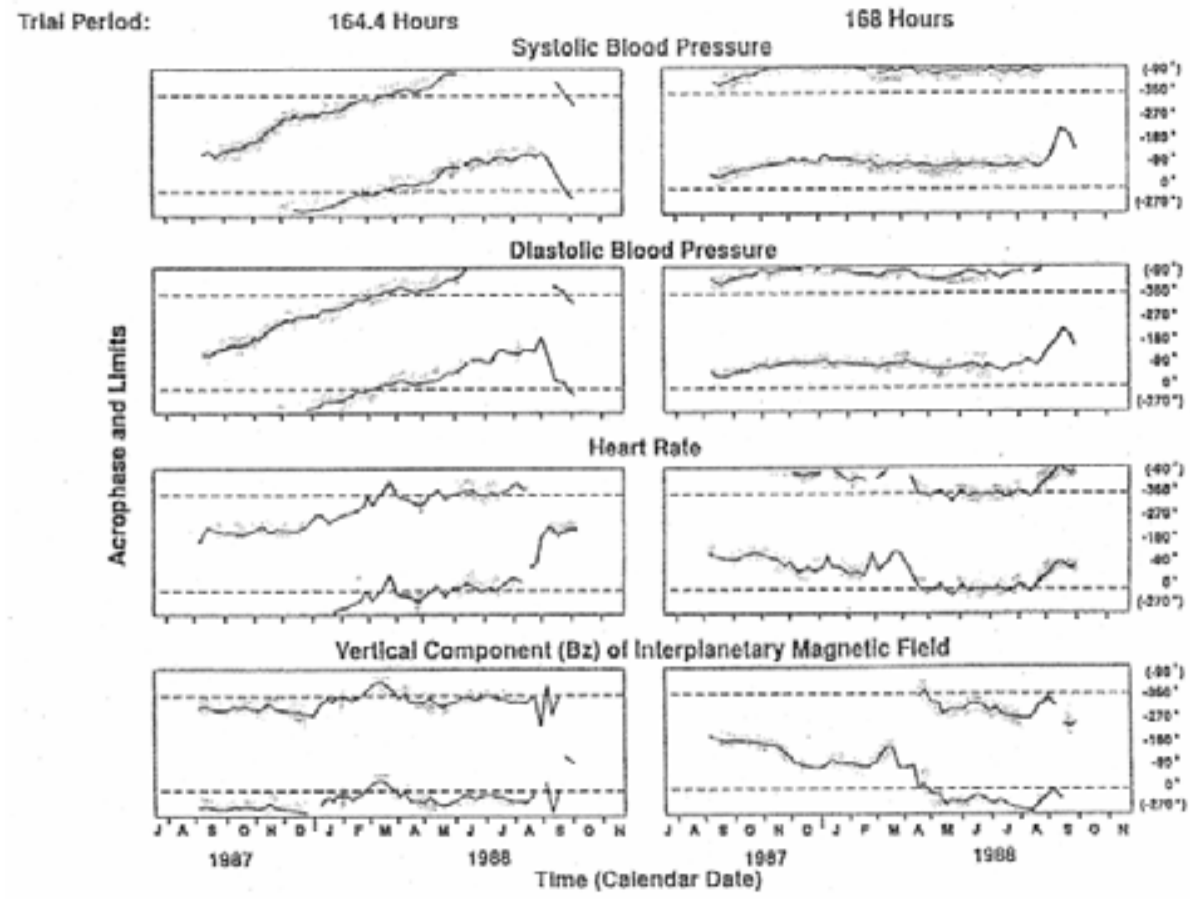

Fig. 8E. Chronobiologic serial sections carried out at a trial period of 164.4 hours (left), corresponding to the period of the north-south component (Bz) of the interplanetary magnetic field (IMF) (bottom), and at a trial period of 168 hours (7 days), corresponding to the societal week (right). BP and HR were measured ambulatorily around the clock, mostly at 15-minute 


\section{Cornélissen et al.: Congruent biospheric and solar-terrestrial cycles}

intervals for about 16 months by a woman 67 years of age at the start of monitoring (rows 1-3). Thicker line segments indicate statistical significance as do dots bracketing the acrophases $(\Phi \mathrm{s})$, corresponding to their CIs. The circaseptan component is mostly statistically significant for all variables, at both trial periods. The acrophase curve of $\mathrm{Bz}$ is horizontal (stable) at a trial period of 164.4 hours, whereas the acrophase curve of BP is more or less horizontal at a trial period of 168 hours. For HR, the time course of acrophases drifts with the 168-hour trial period. The physiological variables are differently synchronized, BP mainly by the societal week and HR pulled by the 164.4-hour period of Bz. In the case of HR, a small acrophase shift occurs more or less in the middle of the monitoring span. This shift in circaseptan acrophase of HR coincides with a similar shift in circaseptan acrophase of Bz. BP clearly drifts away from 164.4 hours (left), further validating the 7-day synchronized component in BP. In the case of HR, there is also a transient drift of the acrophase of the 164.4-hour component for several months, but it is not as pronounced or consistent as that observed for BP. Moreover, there are spans when the 164.4-hour acrophase remains stationary at the beginning of the series and again in the second half of the monitoring span. These are spans when a stable 164.4-hour acrophase is also observed for Bz. From these observations, it appears that Bz may pull HR, and that there is occasional phase-locking as well as period-locking between these two variables. It should be noted further that the acrophase difference between $\mathrm{HR}$ and $\mathrm{Bz}$ at the beginning of the series is about $90^{\circ}$, whereas in the second half of the series the acrophase difference is smaller. This means that when there is frequency-locking between the two variables, this may occur with a different phase difference. Whether or not these phase differences and phase-locking follow a predictable pattern such as being dependent upon the stage of the solar activity cycle remains to be further investigated. These results are only observational at this stage, and a mechanism or model accounting for these observations has not yet been developed. One avenue that seems promising may be to consider the possibility that there is more than a single circaseptan component in geomagnetic disturbance. This was the case for geomagnetic pulsations in Antarctica as well as in geomagnetic indices during some but not all spans that were investigated since the recording of aa (and later of $\mathrm{Kp}$ ) started. One component was close to 7 days and the other was slightly shorter than 7 days. When two components with close periods are present jointly, they may pull during some spans, but not during others, depending upon the relative instantaneous phase difference between the two different components, e.g., whether they are in phase or out of phase.

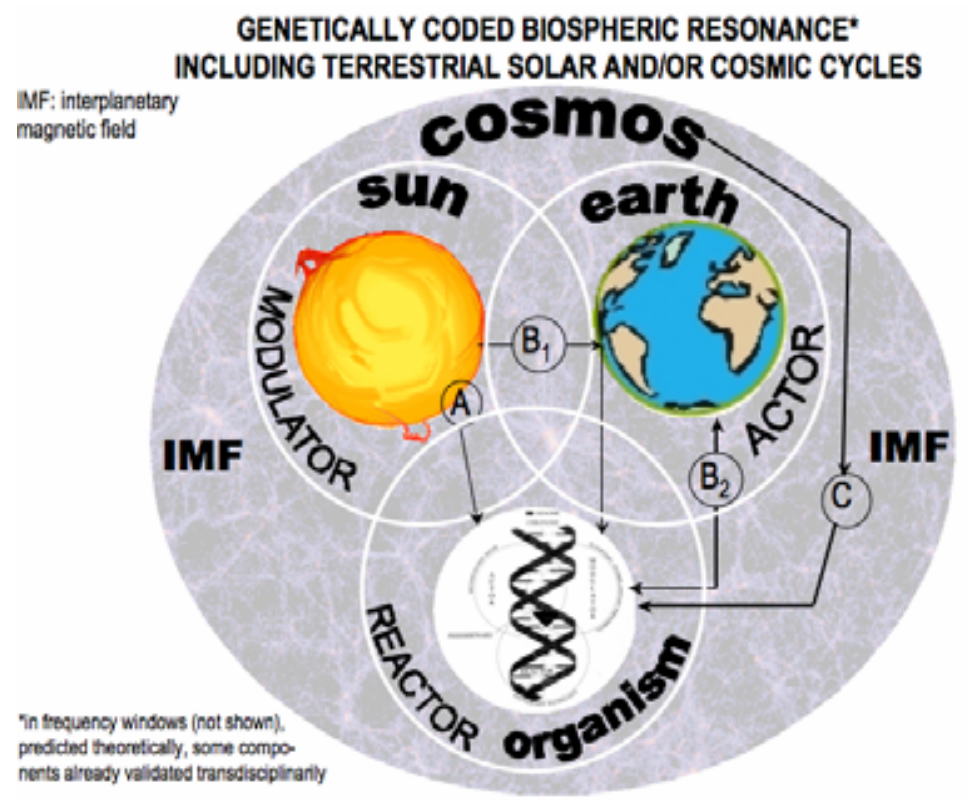

Fig. 8 F. We need not ignore the many signatures of the cosmos with validated statistical significance of anticipated periods that characterize:

a. dozens of decades-long time series of BP and HR;

b. other physiology and psychology, including mental functions;

c. religious proselytism;

d. suicide;

e. sudden cardiac death;

f. terrorist activity for the past 39 years;

g. 2,556 years of international battles compiled by Raymond Holder Wheeler;

h. military expenditures for training in non-medical science;

i. degrees earned;

j. Gallup Polls;

k. political and military actions in nearly 200 years, meta-analyzed from the much broader treasure of data compiled by Alexander Leonidovich Chizhevsky (1921). 
While chance can never be ruled out, it would be further greatly reduced by systematic lifetime monitoring of physiology in health, of pathology and disease, notably in archives to separate effects of sun and earth, many of which are beneficial. Other effects such as extreme cold and heat or extreme light can be met by countermeasures such as housing, heating and air conditioning. The task remains to develop countermeasures to those non-photic effects that can be documented as harmful. While the earth is the immediate actor, and for that action the sun is the modulator, while the biosphere reacts to both terrestrial and solar factors, the roles of actor, reactor and modulator are continuously changing. In the greenhouse effect, organisms are the actors, as shown by a double-headed arrow (B2). There may be other more subtle effects of synchronized human action upon the earth. Original drawing by Mary Sampson.

occurrence of an environmental cycle by the point that it became genetically coded. Damped persistence of the biospheric cycle is a transdisciplinary tool equally pertinent to physics and biology.

Congruence and its selectivity, in the light of subtractive and additive behavior, that assesses the roles of factors from outside vs. inside the biosphere, gain in importance, when the biotic cyclic partner relates to:

1) THE HEALTH of individuals with its alterations serving as early harbingers of risk that prompt measures for stroke and other severe disease prevention (as is the finding of Vascular Variability Disorders, VVDs, pertaining notably to alterations of the circadian rhythm, such as a $\mathrm{BP}$ overswing that carries a risk of developing a cerebral ischemic event in the next 6 years greater than that of an elevated BP itself and can often be treated) (Halberg et al. 2009b) and to

2) THE DISEASES of society, being reflected in the incidence patterns of sudden cardiac death (Halberg et al. 2006), suicide (Cornélissen and Halberg 2006, Halberg et al. 2008a), crime and terrorism (Cornélissen et al. 2007b, Grigoryev and Vladimirskii 2007, Halberg et al. 2007), and possibly leading to measures such as the optimization of the desirable (good) and the elimination, as far as possible, of the undesirable (evil) by appropriate countermeasures.

Rational mechanisms that have to be tested to inquire about causality depend on a subtraction-addition (remove and replace) approach implemented by the cosmos and have thus far shown the persistence with damping of the biotic spectral components when a reciprocal environmental component was lost or buried in noise to the point that it was no longer detectable by available methods and/or there was amplification when the environmental spectral component, previously not detected, became statistically significant, Fig. $8 \mathrm{D}$ and 8E (Cornélissen et al. 1996, Halberg et al. 2006, Sothern et al. 2009b).

Epilogue on method: remove and replace = subtraction and addition in the study of biological circadian rhythms

Removing a gland was a time-honored approach to finding out what the removed gland does, by looking for deficiencies or other alterations and seeing further what replacement of the gland (by transplantation or its hormones) does. This was how endocrinology was reportedly founded by Berthold $(1849,1880)^{5}$. Two cockerels with their testicles removed remained capons (subtraction); two other castrated cockerels (remove $=$ subtraction) that received testicular transplants (replace $=$ addition) developed secondary sexual characteristics, and the concept of substitution therapy evolved.

In 1950, one of us $(\mathrm{FH})$ reported, as others did before him, very large variations along the 24-hour scale in counts of cells staining with a pink dye (eosin): the eosinophil cells (Halberg and Visscher 1950). He also found differences in this variability as a function of genetics. Moreover, the eosinophil counts were depressed by certain adrenocortical hormones and by epinephrine in the presence and in the absence of the adrenal cortex as found in mice (Halberg 1952) with a focus upon the role of chemical structure in exogenous eosinopenia. Best et al. (1952) reported the finding that the eosinophil response to

\footnotetext{
5) The subtraction-addition (removal and replacement) approach was applied to the male gonad by Arnold Adolph Berthold (1803-1861), a founder of endocrinology. Berthold was inspired by Scottish surgeon John Hunter (1728-1793), who had transplanted cock testes into the abdominal cavity of a hen. Berthold castrated four cockerels. Two remained capons (removal = subtraction), while earlier two, who had both testes transplanted into the abdominal cavity of the other (removal and replacement $=$ subtraction and addition), regained their secondary sexual characteristics of growing and aggressiveness. The removal and replacement also applied to other endocrine glands - the adrenal, thyroid and pancreas - and led to substitution treatment pioneered by Charles Edward Brown-Sequard (1817-1861). We now let the aeolian environment do the addition, including amplification, and subtraction, including damping.
} 
epinephrine persisted in patients with their adrenal glands removed (as found in mice by one of us, FH).

In the euphoria of the finding that the adrenal hormone made lame people walk again, adrenal glands were removed in research on humans looking for mechanisms underlying the effect of these "wonder drugs". The opportunity to study patients deprived of their adrenals, a rare event in the history of medical science, revealed that a cycle in eosinophil count was lost in patients (Halberg et al. 1951, cf. Best et al. 1952) without adrenals, as it was lost in adrenalectomized mice (Halberg et al. 1953). The finding held for the circadian rhythm of eosinophil cell counts. In the circadian rhythm of serum iron, there were only changes of the amplitude and the acrophase, after adrenalectomy, but there was no abolition of this rhythm. Some decades later, the ablation of the suprachiasmatic nuclei abolished the circadian rhythm in water drinking, but not that in alcohol drinking or in DNA labeling in the digestive tract, or core temperature (Cornélissen and Halberg 1994, Cornélissen et al. 2002).

The team of Jerome W. Conn (of Conn Syndrome fame) confirmed the finding in adrenocortical insufficiency of the eosinophil rhythms' disappearance and showed, in addition, that replacement with a single large dose at the right time, but not with divided smaller doses, of oral cortisone re-induced the rhythm (Kaine et al. 1955). The approach by "remove" (subtraction) was thus again complemented by "replace" (addition). The approach by subtraction was extended in the earliest 1950s beyond gland removal to the study of other mechanisms of the eosinophil rhythm. When the eyes (receptors of a synchronizing lighting cycle) were "subtracted" by surgery or genetics (in ZRD mice born blind), a previously 24-hour synchronized cycle in activity, while it did not disappear, was free-running from the 24-hour routine, with a built-in near 1-day, but not of precisely 24-hour length (Halberg 1954, Halberg et al. 1954). A circadian desynchronization was already documented by periodograms (that took a week to compute on a desk calculator and another week to check) and were the topic of a discussion by $\mathrm{FH}$ with Julius Bartels in 1953 (Halberg 2000), to indicate that the latter's harmonic dial could also be used flexibly for fitting anticipated desynchronized environmental cycles and not necessarily only a precise 1 -year or 1-day period.

"Circadian" was coined - in the early 1950s, and endorsed by international nomenclature committees years later (Halberg 1959) - both to indicate partial endogenicity and (another reason for "circa" that is too often forgotten) to refer to the also-encountered variability inherent in the cycle's characteristics.
"Circadian" was intended to replace "diurnal", a term used in medicine and zoology to distinguish activity or morbidity patterns during the daily photofraction from those during the daily scotofraction, as diurnality vs. nocturnality, respectively. While they are obvious signatures of the photic day, circadians are also influenced non-photically by natural and artificial electric fields (Wever 1979) and by subtle environmental factors in caves (Halberg et al. 1998). Circadian timing accounts for the difference between about $75 \%$ survival vs. about $75 \%$ death from the same dose of a cardiac drug, among others, under controlled laboratory conditions as a function of timing (Halberg and Stephens 1959).

In dealing with diseases of society, the environmental global monitoring started with magnetometers by Gauss, Humboldt and Sabine must be extended to humans, in order to understand, eventually to treat and ideally to prevent diseases of society. Here the remove-and-replace approach has its precedence in air conditioning to remove undue heat and heating to replace lacking acceptable temperatures. Just as the cosmos determines temperatures, it also has effects that we can study as a follow-up on the remove-and-replace approach in endocrinology, chronomics and environmental temperature control in homes and eventually in habitats. For instance, it has been shown that circaseptans in human HR are expressed more prominently when this component is detectable in the rate of change in sunspot area (Cornélissen and Halberg 1994, Cornélissen et al. 1996).

\section{CONCLUSION}

We systematically monitor climate for physical variables related to weather. In human affairs, surveillance is extended to garages to prevent crimes, and small rodents to develop drugs, but not those for whom the drugs are intended. It took over half a century before voices to monitor blood sugar of patients with insulin-dependent diabetes were heard. Monitoring BP is equally timely, technically feasible for individualized improved home and website-based personalized care, while also serving basic science. Someday perhaps the prevention of societal illness, a task for scholars of the geo- and cosmo-physical as well as of biomedical sciences will be implemented by and for every person, just as alphabetism, the fourth " $R$ " for rhythm in education has become a universal desideratum. It took a long time for antisepsis to become accepted. Just as one bacterium can multiply and lead to severe sepsis or as one 
cancer cell can develop into a lethal malignancy, so one pathogenetic individual can "infect" a population and lead to disaster in populations. It is the more urgent to identify and separate, by congruence and "remove and replace" approaches the helio-geomagnetic and other influences that unseen act powerfully upon us, Fig. 8F, contributing in certain geographic regions to the patterns of sudden cardiac death, suicide and terrorism.

\section{ACKNOWLEDGEMENT}

GM-13981 (FH) and University of Minnesota Supercomputing Institute (GC, FH).

\section{REFERENCES}

Bartels J. Statistical studies of quasi-periodic variables: with illustrative examples from geophysics (Reprints of three papers from Terr Mag Atmosph Electr). Carnegie Institution of Washington, Washington DC 1959.

Berthold AA. Fragment einer Selbstbiographie von Arnold Adolph Berthold. Deut Arch Gesch Med med Geogr. 3: 74-100, 1880.

Berthold AA. Transplantation der Hoden. Arch. Anat. Physiol. Wissenschr. Med., 1849. pp. 42-46; translated by Quiring DP, Transplation of Testes. Bull Hist Med. 16: 339-401, 1944.

Best WR, Muehrcke RC, Kark RM. Studies on adrenocortical eosinopenia: a clinical and statistical evaluation of four-hour eosinophil response tests. J Clin Invest. 31: 733-742, 1952.

Broda H, Brugge D, Homma K, Hastings JW. Circadian communication between unicells? Effects on period by cell-conditioning of medium. Cell Biophys. 8: 47-67, 1986.

Chibisov SM. Resolution concerning chronobiology and chronomics. III International Conference, Civilization diseases in the spirit of V. I. Vernadsky, People's Friendship University of Russia, Moscow, Oct. 10-12, 2005, p. 23-25.

Chizhevsky AL. Astronomy, Psychology and History. M. A. Institute, Moscow 1921, 78 pp.

Cornélissen G, Halberg F. Introduction to Chronobiology. Medtronic Chronobiology Seminar \#7, April 1994, 52 pp.

Cornélissen G, Halberg F. Chronomedicine. In Armitage P, Colton T (eds.): Encyclopedia of Biostatistics, $2^{\text {nd }}$ ed., John Wiley \& Sons Ltd, Chichester 2005, p. 796-812.
Cornélissen G, Halberg F. Chronomics of suicides and the solar wind. Br J Psychiatry. 189: 567-568, 2006.

Cornélissen G, Broda H, Halberg F. Does Gonyaulax polyedra measure a week? Cell Biophys. 8: 69-85, 1986.

Cornélissen G, Halberg F, Wendt HW, Bingham C, Sothern RB, Haus E, Kleitman E, Kleitman N, Revilla MA, Revilla M, Jr., Breus TK, Pimenov K et al. Resonance of about-weekly human heart rate rhythm with solar activity change. Biologia (Bratisl). 51: 749-756, 1996.

Cornélissen G, Kanabrocki E, Halberg J, Halberg F. Toward the chronobiology and chronomics of the intestine. In Zabielski R, Gregory PC, Weström B (eds.): Biology of the Intestine in Growing Animals. Elsevier NV, Amsterdam 2002, p. 751-804.

Cornélissen G, Halberg F, Pöllmann L, Pöllman B, Katinas GS, Minne H, Breus T, Sothern RB, Watanabe Y, Tarquini R, Perfetto F, Maggioni C et al. Circasemiannual chronomics: half-yearly biospheric changes in their own right and as a circannual waveform. Biomed Pharmacother. 57 (Suppl. 1): 45s-54s, 2003.

Cornélissen G, Masalov A, Halberg F, Richardson JD, Katinas GS, Sothern RB, Watanabe Y, Syutkina EV, Wendt HW, Bakken EE, Romanov Y. Multiple resonances among time structures, chronomes, around and in us. Is an about 1.3-year periodicity in solar wind built into the human cardiovascular chronome? Human Physiol. 30: 86-92, 2004.

Cornélissen G, Halberg F, Rostagno C, Otsuka K. A chronomic approach to cardiac arrhythmia and sudden cardiac death. Auton Nerv Syst. 44: 251-254, 2007a.

Cornélissen G, Halberg F, Wendt HW, Sothern RB, Chibisov SM, Kulikov SI, Agarwal RK. Weak magnetoperiodism rather than socio-photothermoperiodism characterizes human terrorism detection of about 1.3-year aeolian transyear but not precise 1.0-year cycle. In Frolov VA, Grinina OV, Agarwal RK (eds.): Proc. $8^{\text {th }}$ Intern. Congr. "Health and Education in XXI ${ }^{\text {st }}$ Century", Moscow, Russia, November 14-17, 2007b, p. 77-80.

Cornélissen G, Tarquini R, Perfetto F, Otsuka K, Gigolashvili M, Halberg F. About 5-month cycle in human circulating melatonin: signature of weather in extraterrestrial space? Poster presentation, Fourth UN/ESA/NASA/JAXA Workshop on the International Heliophysical Year 2007 and Basic Space Science: "First Results 
from the International Heliophysical Year 2007", Sozopol, Bulgaria, June 2-6, 2008.

Cornélissen G, Halberg F, Sonkowsky R, Siegelová J, Homolka P, Dušek J, Fišer B. Meta-analysis of Horrebow's and Schwabe's scholarship with a view of sampling requirements. In Halberg F, Kenner T, Fišer B, Siegelová J: Proc. Noninvasive Methods in Cardiology, Brno, Czech Republic, July 7-10, 2009, p. 141-158.

Dewey ER, Mandino O. Cycles: The Mysterious Forces That Trigger Events. Hawthorn, New York $1971,211 \mathrm{pp}$.

Ertel S. Space weather and revolutions: Chizhevsky's heliobiological claim scrutinized. Studia Psychol (Bratisl). 39: 3-22, 1996.

Fraser-Smith AC. Spectrum of the geomagnetic activity index Ap. J Geophys Res. 77: 4209-4220, 1972.

Grigoryev PYe, Vladimirskii BM. The cosmic weather affects the terrorist activity. Uchenye zapiski Tavricheskogo Natsionalnogo Universiteta im V. I. Vernadskogo, Series "Biology, chemistry" 20 (59) (No. 1): 28-46, 2007.

Halberg F. Some correlations between chemical structure and maximal eosinopenia in adrenalectomized and hypophysectomized mice. J Pharmacol Exp Ther. 106: 135-149, 1952.

Halberg F. Beobachtungen über 24 Stunden-Periodik in standardisierter Versuchsanordnung vor und nach Epinephrektomie und bilateraler optischer Enukleation, 20 ${ }^{\text {th }}$ Meet. German Physiol. Soc., Homburg/Saar, September, 1953. Berichte über die gesamte Physiologie und experimentelle Pharmakologie (Berichte über die gesamte Biologie, Abteilung B) 162: 354-355, 1954. [English translation of Aschoff's remark in Halberg $F$ et al. Transdisciplinary unifying implications of circadian findings in the 1950s. J Circadian Rhythms 1: 2, 2003. 61 pp, see p. 23.]

Halberg F. Physiologic 24-hour periodicity; general and procedural considerations with reference to the adrenal cycle. Z Vitam Hormon Fermentforsch. 10: 225-296, 1959.

Halberg F. Chronobiology: methodological problems. Acta Med Rom. 18: 399-440, 1980.

Halberg F. Historical encounters between geophysics and biomedicine leading to the Cornélissen-series and chronoastrobiology. In Schröder W (ed.): Long- and Short-Term Variability in Sun's History and Global Change. Science Edition, Bremen 2000, p. 271-301.

Halberg F, Visscher MB. Regular diurnal physiological variation in eosinophil levels in five stocks of mice. Proc Soc Exp Biol (NY). 75: 846-847, 1950.
Halberg F, Stephens AN. Susceptibility to ouabain and physiologic circadian periodicity. Proc Minn Acad Sci. 27: 139-143, 1959.

Halberg F, Conner RL. Circadian organization and microbiology: Variance spectra and a periodogram on behavior of Escherichia coli growing in fluid culture. Proc Minn Acad Sci. 29: 227-239, 1961.

Halberg F, Visscher MB, Flink EB, Berge K, Bock F. Diurnal rhythmic changes in blood eosinophil levels in health and in certain diseases. J Lancet71: 312-319, 1951.

Halberg F, Visscher MB, Bittner JJ. Eosinophil rhythm in mice: Range of occurrence; effects of illumination, feeding and adrenalectomy. Amer J Physiol. 174: 109-122, 1953.

Halberg F, Visscher MB, Bittner JJ. Relation of visual factors to eosinophil rhythm in mice. Amer J Physiol. 179: 229-235, 1954.

Halberg F, Johnson EA, Nelson W, Runge W, Sothern R- Autorhythmometry - procedures for physiologic self-measurements and their analysis. Physiol Teach. 1: 1-11, 1972.

Halberg F, Breus TK, Cornélissen G, Bingham C, Hillman DC, Rigatuso J, Delmore P, Bakken E. International Womb-to-Tomb Chronome Initiative Group: Chronobiology in space. Keynote, $37^{\text {th }}$ Annu. Meet. Japan Soc. for Aerospace and Environmental Medicine, Nagoya, Japan, November 8-9, 1991. University of Minnesota/Medtronic Chronobiology Seminar Series, \#1, December 1991, 21 pp.

Halberg F, Cornélissen G, Sonkowsky RP, Lanzoni C, Galvagno A, Montalbini M, Schwartzkopff O. Chrononursing (chronutrics), psychiatry and language. New Trends Exp Clin Psychol. 14: 15-26, 1998.

Halberg F, Cornélissen G, Otsuka K, Watanabe Y, Katinas GS, Burioka N, Delyukov A, Gorgo Y, Zhao ZY, Weydahl A, Sothern RB, Siegelová J et al. International BIOCOS Study Group. Cross-spectrally coherent $\sim 10.5$ - and 21-year biological and physical cycles, magnetic storms and myocardial infarctions. Neuro Endocrinol Lett. 21: 233-258, 2000.

Halberg F, Cornélissen G, Otsuka K, Schwartzkopff O, Halberg J, Bakken EE. Chronomics. Biomed Pharmacother. 55 (Suppl. 1): 153s-190s, 2001.

Halberg F, Cornélissen G, Katinas G, Appenzeller O, Otsuka K, Sothern RB, Tarquini R, Perfetto F, Maggioni C, Wilson D, Schröder W, Schwartzkopff O et al. System times and time horizons for biospheric near-matches of primarily non-photic environmental cycles. Biomed Pharmacother. 56 (Suppl. 2): 266s-272s, 2002. 
Halberg F, Cornélissen G, Bingham C, Witte H, Ribary U, Hesse W, Petsche H, Engebretson M, Geissler H-G, Weiss S, Klimesch W, Rappelsberger $\mathrm{P}$ et al. Chronomics: Imaging in time by phase synchronization reveals wide spectral-biospheric resonances beyond short rhythms. ("Wenn man über kurze Rhythmen hinausgeht") In memoriam - lost future: Dr.-Ing. habil. Dr. rer. nat. Barbara Schack: 1952-2003. Neuro Endocrinol Lett. 24: 355-380, 2003 a.

Halberg F, Cornélissen G, Schack B, Wendt HW, Minne H, Sothern RB, Watanabe Y, Katinas G, Otsuka K, Bakken EE. Blood pressure self-surveillance for health also reflects 1.3-year Richardson solar wind variation: spin-off from chronomics. Biomed Pharmacother. 57 (Suppl. 1): 58s-76s, 2003b.

Halberg F, Cornélissen G, Regal P, Otsuka K, Wang ZR, Katinas GS, Siegelová J, Homolka P, Přikryl P, Chibisov SM, Holley DC, Wendt RW et al. Chronoastrobiology: proposal, nine conferences, heliogeomagnetics, transyears, near-weeks, near-decades, phylogenetic and ontogenetic memories. Biomed Pharmacother. 58 (Suppl. 1): S150-S187, 2004.

Halberg F, Cornélissen G, Katinas G, Tvildiani L, Gigolashvili M, Janashia K, Toba T, Revilla M, Regal P, Sothern RB, Wendt HW, Wang ZR et al. International BIOCOS Group. Chronobiology's progress: season's appreciations 2004-2005. Time-, frequency-, phase-, variable-, individual-, age- and site-specific chronomics. J Appl Biomed. 4: 1-38, 2006.

Halberg F, Cornélissen G, Sothern RB, Chibisov SM, Wendt HW. Do unseen, very weak magnetic mechanisms contribute to terrorism in wobbly spectral windows? In Frolov VA, Grinina OV, Agarwal RK (eds.): Proc. $8^{\text {th }}$ Intern. Congr. "Health and Education in XXI ${ }^{\text {st }}$ Century", Moscow, Russia, November 14-17, 2007, p. 63-66.

Halberg F, Cornélissen G, Berk M, Dodd S, Henry M, Wetterberg L, Nolley E, Beaty L, Siegelová J, Fišer B, Wolff C. BIOCOS project. Solar signatures in Australian suicide incidence: gender differences in prominence of photic vs. nonphotic spectral components. In Halberg F, Kenner T, Fišer B, Siegelová J (eds.): Proc. Noninvasive Methods in Cardiology, Brno, Czech Republic, October 4-7, 2008a, p. 44-62.

Halberg F, Cornélissen G, Schwartzkopff O. Quo vadis chronomics 2008: Measuring variability in us, among us and around us. In Halberg F, Kenner T, Fišer B, Siegelová J (eds.): Proc. Noninvasive Methods in Cardiology, Brno, Czech Republic, October 4-7, 2008b, p. 16-25.
Halberg F, Cornélissen G, Sothern RB, Katinas GS, Schwartzkopff O, Otsuka K. Cycles tipping the scale between death and survival (= "life"). Progr of Theor Physics. 173 (Suppl): 153-181, 2008c.

Halberg F, Cornelissen G, Sothern RB, Otsuka K, Revilla M, Siegelová J, Fišer B. Circadian stage-dependent infradian-modulated changes in a mental function during aging. In Halberg F, Kenner T, Fišer B, Siegelová J (eds.): Proc. Noninvasive Methods in Cardiology, Brno, Czech Republic, October 4-7, 2008d, p. 26-31.

Halberg F, Cornélissen G, Best WR. A transtridecadal BEL cycle in human blood pressure and body weight. In Halberg F, Kenner T, Fišer B, Siegelová J (eds.): Proc. Noninvasive Methods in Cardiology, Brno, Czech Republic, July 7-10, 2009a, p. 257-270.

Halberg F, Cornélissen G, Otsuka K, Siegelová J, Fišer B, Dušek J, Homolka P, Sánchez de la Peña $\mathrm{S}$, Singh RB. BIOCOS project. Extended consensus on means and need to detect vascular variability disorders (VVDs) and vascular variability syndromes (VVSs). Leibniz-Online $\mathrm{Nr}$. 5, 2009b. 35 pp.

Halberg F, Cornélissen G, Siegelová J, Homolka P, Dušek J, Fišer B. Differences in time structural environmental congruence of vascular variables in an elderly man. In Halberg F, Kenner T, Fišer B, Siegelová J (eds.): Proc. Noninvasive Methods in Cardiology, Brno, Czech Republic, July 7-10, 2009c, p. 271-280.

Halberg F, Cornélissen G, Sothern RB, Czaplicki J, Schwartzkopff O. 35-year climate cycle in heliogeophysics, psychophysiology, military politics, and economics [In Russian]. Geophys Proc Biosph. 8 (No 2): 13-42, 2009d.

Han HW, Shao DL, Wu JY, Cornélissen G, Halberg F. Chronobiologic approach to beat-to-beat variations of cultured murine myocardial cells. Cell Biophys. 18: 217-229, 1991.

Hanson BR, Halberg F, Tuna N, Bouchard TJ, Jr., Lykken DT, Cornélissen G, Heston LL. Rhythmometry reveals heritability of circadian characteristics of heart rate of human twins reared apart. Cardiologia. 29: 267-282, 1984.

Hoogerwerf WA, Hellmich HL, Cornélissen G, Halberg F, Shahinian VB, Bostwick J, Savidge TC, Cassone VM. Clock gene expression in the murine gastrointestinal tract: endogenous rhythmicity and effects of a feeding regimen. Gastroenterology. 133: 1250-1260, 2007.

Kaine HD, Seltzer HS, Conn JW. Mechanism of diurnal eosinophil rhythm in man. J Lab Clin Med. 45: 247-252, 1955.

Kováč M, Mikulecký M. Secular rhythms and Halberg's paraseasonality in the time occurrence 
of cerebral stroke. Bratisl Med J. 106: 423-427, 2005.

Kováč M, Mikulecký M. Time sequence of epileptic attacks from the point of view of possible lunisolar connections. Intern. Conf. Frontiers of Biomedical Science: Chronobiology, Chengdu, China, September 24-26, 2006, p. 175-179.

Makarov VI, Sivaraman KR. New results concerning the global solar cycle. Solar Phys. 123: 367-380, 1989.

Marquardt DW. An algorithm for least-squares estimation of nonlinear parameters. J Soc Ind Appl Math. 11: 431-441, 1963.

Mikulecký M. Reanalysis of natality in South Brazil. Halberg's paraseasonality dominating again. Intern. Conf. Frontiers of Biomedical Science: Chronobiology, Chengdu, China, September 24-26, 2006, p. 187-188.

Mikulecký M. Solar activity, revolutions and cultural prime in the history of mankind. Neuro Endocrinol Lett. 28: 749-756, 2007.

Mikulecký M, Florida PL. Daily birth numbers in Davao, Philippines, 1993-2003: Halberg's transyear stronger than year. Abstr. $26^{\text {th }}$ Seminar, Man in His Terrestrial and Cosmic Environment, Úpice, Czech Republic, May 17-19, 2005.

Prestes A, Rigozo NR, Echer E, Vieira LEA. Spectral analysis of sunspot number and geomagnetic indices (1868-2001). J Atmosph Sol-Terr Phys. 68: 182-190, 2006.

Refinetti R, Cornélissen G, Halberg F. Procedures for numerical analysis of circadian rhythms. Biol Rhythm Res. 38(4): 275-325, 2007.

Roederer JG. Are magnetic storms hazardous to your health? Eos, Trans Am Geophys Union. 76: 441, 444-445, 1995.

Sabine E. On periodical laws discoverable in the mean effects of the larger magnetic disturbances. No. II. Philos Trans R Soc Lond. 142: 103-124, 1852.
Schweiger H-G, Berger S, Kretschmer H, Mörler H, Halberg E, Sothern RB, Halberg F. Evidence for a circaseptan and a circasemiseptan growth response to light/dark cycle shifts in nucleated and enucleated Acetabularia cells, respectively. Proc Natl Acad Sci USA. 83: 8619-8623, 1986.

Sothern RB, Cornélissen G, Yamamoto T, Takumi T, Halberg F. Time microscopy of circadian expression of cardiac clock gene mRNA transcription: chronodiagnostic and chronotherapeutic implications. Clin Ter. 160(2): e25-e34, 2009a.

Sothern RB, Yamamoto T, Cornélissen G, Takumi T, Halberg F. Central and peripheral circadian clock genes, their statistical analysis for rhythms, and relationship to health and disease. Scripta Med (Brno). 82: 133-163, 2009b.

Takumi T, Yamamoto T, Cornélissen G, Hoogerwerf WA, Halberg F. Peripheral murine clock gene variation and extent of synchronization. Proc. Intern. Conf. Frontiers of Biomedical Science: Chronobiology, Chengdu, China, September 24-26, 2006, p. 228-231.

Ulmer W, Cornélissen G, Halberg F. Physical chemistry and the biologic week in the perspective of chrono-oncology. In Vivo. 9: 363-374, 1995.

Vladimirskii BM, Narmanskii VYa, Temuriantz NA. Global rhythmics of the solar system in the terrestrial habitat. Biophysics. 40: 731-736, 1995.

Wever RA. The Circadian System of Man: Results of Experiments under Temporal Isolation. Springer-Verlag, New York 1979, 276 pp.

Yamamoto T, Nakahata Y, Soma H, Akashi M, Mamine T, Takumi T. Transcriptional oscillation of canonical genes in mouse peripheral tissues. BMC Mol Biol. 5: 18, 2004. 


\section{APPENDIX}

\section{Inferential statistical considerations and test for congruence between cosmos and biosphere}

Abstract. In a set of variables self-rated or self-measured for up to 40 years by RBS, a newly developed congruence test detects statistically significant associations with SWS and the antipodal geomagnetic index aa, in mental functions, such as a 1-minute estimation, mood and vigor and in SBP and, for the case of SWS, also in HR.

Problem. Solar terrestrial associations may no longer mean, as Sabine claimed with limited available data to him, that sunspot numbers and geomagnetism are identical in their time course, yet an effect of the Sun upon magnetism on Earth seems to be established (Bartels 1959). The effect on the biosphere of helioand/or geomagnetism, in turn, is not yet generally accepted. Tables 1 and 2 , in turn suggest that by the criterion of overlying or at least overlapping CIs of the periods of a biospheric and a physical time series being compared, called congruence, there is at least as good an association (actually a numerically better one) of biospheric periods that correspond to those in the solar wind as there is congruence between helioand geomagnetics. Nonetheless, there remains the need to rule out chance in all ways possible, our concern herein.

In almost all cases, the various time series in Tables 1 and 2 consist of weekly means covering a 40 -year span, giving a total of 2,080 $(40 \times 52)$ data points. All periods between $1 / 3$ year and 2.5 years were considered. In terms of Fourier frequencies, the $1 / 3$-year is $120(3 \times 40)$ cycles in the data and the 2.5-year period is 16 cycles in the data, for a total of 105 Fourier frequencies $(=120-16+1)$. So, if we let $\mathrm{N}$ denote the number of frequencies under consideration, $\mathrm{N}=105$. (If, instead of 40 , we considered 35 years, we would have $\mathrm{N}=115-14+$ $1=102$, and results would not differ markedly from those obtained for $N=105$ ). Because we will only be dealing with one biological and one cosmological time series at a time, our notation can be simple and avoid subscripts. We condition on the cosmological frequencies reported, and, in essence, assume that they constitute all and only those frequencies that matter in each of the cosmological data set. That is, we ignore the fact that they resulted from data analysis and may have errors of omission (type II errors) and spuriousness (type I errors). We denote the number of frequencies at which a signal is detected for the environmental variable used as reference by $\mathrm{U}$ (for universe), rather than $\mathrm{C}$ for cosmolological, because $\mathrm{C}$ could also stand for congruent and/or common and thus may be confusing.
For each biological sequence, we have three related random variables:

1) $B=$ total number of frequencies corresponding to a statistically significant component.

2) $\mathrm{C}=$ number of biological frequencies with non-zero amplitude in common with the cosmological series.

3) $\mathrm{A}=$ number of biological frequencies that are NOT in common with the cosmological series.

Relationship: $\mathrm{B}=\mathrm{A}+\mathrm{C}$. The actual values assumed by these random variables will be denoted $a^{*}, b^{*}$ and $c^{*}$.

Let us define congruence as the proportion of biological frequencies found in the cosmological series, $\mathrm{C} / \mathrm{U}(\mathrm{CU})$. The larger $\mathrm{C} / \mathrm{U}$, the stronger is the congruence.

We assume that $\mathrm{N}$ and $\mathrm{U}$ are fixed and known.

We assume that the frequencies in $\mathrm{B}$ are found by standard 2-degree of freedom $F$ tests at $P=0.05$, and that all are equally likely.

The probability $\operatorname{Pr}(\mathrm{B}=\mathrm{b})$ can be expressed as a hypergeometric $\operatorname{Pr}(\mathrm{C}=\mathrm{c} \mid \mathrm{B}=\mathrm{b})$ times a binomial $\operatorname{Bin}(\mathrm{N}$, $0.05)$.

Results. Computations of P-values for associations of several biological variables with the antipodal geomagnetic disturbance index (aa) and for solar wind speed (SWS) as a measure of congruence are listed in Table 3.

Discussion. We have explored a test to assess whether the degree of congruence in statistically significant frequencies between two different time series with overlying or overlapping CIs (95\% confidence intervals of their periods estimated by nonlinear least squares) is greater than would be expected by chance. An earlier test conditioned on the total number of frequencies examined and the number of frequencies found in each series, using the hypergeometric as the null distribution. It gave a one-sided P-value. The test presented herein is designed for the situation where the frequencies in one of the series are well accepted, but in the other series, they are just being found by data analysis, counting each one with an amplitude statistically significantly different from zero. In the examples considered, there was no control for multiple comparisons and each frequency was tested at $2 \alpha=0.05$. The method could be adapted to other ways of choosing $\alpha$, of course. The test conditions on the total number of frequencies examined and the number found in the well-understood series, but under the null model, assumed that $\mathrm{B}$, the number of frequencies found in the exploratory series, was distributed as a Binomial (N, 0.05). Conditional on B, the number of frequencies congruent between the two series has the hypergeometric distribution given 
Table 3. P-values for associations of several biological variables with the antipodal geomagnetic disturbance index aa and with solar wind speed (SWS) as a measure of congruence.

\begin{tabular}{ccccccc}
\hline $\begin{array}{c}\text { Biological } \\
\text { variable }\end{array}$ & $\mathrm{N}$ & $\mathrm{U}$ & $\mathrm{c}^{*}$ & $\mathrm{a}^{*}$ & $\mathrm{CU}$ & P-value \\
\hline 1MTE & 105 & 11 & with respect to a & & & \\
Mood & 105 & 11 & 6 & 6 & 0.64 & $1.74 \times 10^{-7}$ \\
Vigor & 105 & 11 & 3 & 5 & 0.55 & $1.76 \times 10^{-6}$ \\
SBP & 105 & 11 & 3 & 8 & 0.27 & 0.010 \\
DBP & 105 & 11 & 1 & 6 & 0.09 & 0.015 \\
HR & 105 & 11 & 2 & 5 & 0.18 & 0.368 \\
OT & 105 & 11 & 2 & 7 & 0.18 & 0.072 \\
& & & with respect to SWS & & & \\
1MTE & 105 & 18 & 7 & 6 & 0.39 & $1.30 \times 10^{-5}$ \\
Mood & 105 & 18 & 6 & 3 & 0.33 & $6.24 \times 10^{-5}$ \\
Vigor & 105 & 18 & 5 & 3 & 0.28 & $5.63 \times 10^{-4}$ \\
SBP & 105 & 18 & 5 & 6 & 0.28 & $1.34 \times 10^{-3}$ \\
DBP & 105 & 18 & 1 & 6 & 0.06 & 0.548 \\
HR & 105 & 18 & 3 & 4 & 0.17 & 0.035 \\
OT & 105 & 18 & 3 & 6 & 0.17 & 0.051 \\
\hline
\end{tabular}

1MTE: 1-minute time estimation; SBP and DBP: systolic and diastolic blood pressure; HR: heart rate; OT: oral temperature.

above. The actual computation of the test, however, was motivated by a measure of congruence, $\mathrm{CU}$, defined as the proportion of biological frequencies found in the well-accepted environmental series (used as reference) that were congruent. The P-value was computed as the probability of getting $\mathrm{CU}$ at least as great as in the data. All other things being equal, the test has smaller P-values as $\mathrm{N}$ increases. The test yields P-values, as a (for us) indispensable step in exploring associations of the biosphere with the terrestrial and solar environments. Those in Table 3 explore in inferential statistical terms at least one aspect of the uncertainties involved. There is no test-statistic per se and no confidence interval, which will have to be estimated for CU.

General Discussion. Even though one must not compare probabilities, it seems intuitively right that the most statistically significant results relate to a mental function, namely a 1-minute time estimation, and to mood and also to vigor. The cosmos has as a primary target the central nervous system, insofar as it influences terrorism, religious proselytism, suicide and electrical accidents of the heart.

It is satisfying to find statistical significance in the congruence of SBP with both SWS and aa. Ambulatory BP and HR monitoring is of importance for the preventive care of each individual, yet the same data collection also serves for the monitoring of the effects of helio-geomagnetism upon the behavior of populations. Supporting this possibility is an observation that after a transyear in SWS is no longer detected, there is a subsequent damping and partial loss after a lag of a single transyear cycle of the same component in the SBP of FH (Halberg et al. 2006).

The concept of congruence is most applicable for components in the para-annual and para-semiannual 
frequency ranges of the spectrum, where "medium frequencies" will vary as a function of the length of the time series and the sampling interval. Problems in the "low" frequency range relate to the poor resolution of components that can only be estimated with very wide confidence intervals of their periods. In other words, two components may be found to be congruent, even though they are not, only because of a lack of resolution in frequency. This argument seems particularly pertinent to period lengths that approach the human lifespan and/or do not allow replication without the interference of changes with age.

In dealing with congruence, there is a great need for standardization:

- The time series should be of similar (preferably same) length.

- The time series should cover similar (preferably same) spans.

- The time series should have similar (preferably same) sampling rate.

- The time series should be checked for gaps, as missing data may yield spurious spectral peaks when gaps are either too long or too numerous.

- The data may need detrending prior to the computation of (e.g., least-squares) spectra.

- The spectral range should be specified a priori.

- For signals in the higher frequency range of the spectrum, analyses could be applied to adjacent, non-overlapping subsections of the original time series to check for consistency as a function of time.

- For signals in the lower frequency range of the spectrum, it is helpful to find replications by considering similar time series from different individuals or mortality/morbidity statistics from several geographic locations.
- To avoid interference from spurious sidelobes, analyses should be repeated after systematically changing the length of the time series by removing small numbers of data at the beginning and/or end of the series.

- To deal with partly non-stationary signals, phase information can be obtained by chronomic serial sections. Global congruence in period does not imply a parallelism in phase behavior.

- All statements of congruence must not be extended beyond the scope of the data investigated and in particular not beyond the spans of time covered by observations. In the case of the variable sun, there is always a chance for the unexpected. In this context, we cite General Sir Edward Sabine, who wrote in 1852, in the light of then-current data:

“... it is certainly a most striking coincidence, that the period, and the epochs of minima and maxima, which M. Schwabe has assigned to the variation of the solar spots, are absolutely identical with those which have here been assigned to the magnetic variations" (Sabine 1852). Likewise, Fraser-Smith (1972) was correct in reporting only a 7-day component for geomagnetics in the light of the data available to him, although his conclusion must be qualified in the light of subsequently collected data.

Happenstance can never be ruled out, but must be estimated and rendered unlikely by further steps. Future research into the potential role of the sun has much to gain from physiological monitoring taking place in preventive and curative self-surveillance strategies taught and implemented in primary, secondary and adult education, and supported by an international website. 